Check for updates

Cite this: Food Funct., 2021, 12, 3799

\section{Green and white teas as health-promoting foods}

\author{
Daniel Hinojosa-Nogueira, ${ }^{a}$ Sergio Pérez-Burillo, ${ }^{a, b}$ Silvia Pastoriza de la Cueva ${ }^{a}$ and \\ José Ángel Rufián-Henares (D) *a,c
}

Received 25th January 2021, Accepted 10th March 2021

DOI: $10.1039 / \mathrm{d} 1 \mathrm{fo} 00261 \mathrm{a}$

rsc.li/food-function

\begin{abstract}
Tea is one of the most consumed beverages around the world and as such, it is constantly the object of novel research. This review focuses on the research performed during the last five years to provide an updated view of the current position of tea regarding human health. According to most authors, tea health benefits can be traced back to its bioactive components, mostly phenolic compounds. Among them, catechins are the most abundant. Tea has an important antioxidant capacity and anti-inflammatory properties, which make this beverage (or its extracts) a potential aid in the fight against several chronic diseases. On the other hand, some studies report the possibility of toxic effects and it is advisable to reduce tea consumption, such as in the last trimester of pregnancy. Additionally, new technologies are increasing researchers' possibilities to study the effect of tea on human gut microbiota and even against SARS CoV-2. This beverage favours some beneficial gut microbes, which could have important repercussions due to the influence of gut microbiota on human health.
\end{abstract}

\section{Introduction}

\subsection{Tea throughout history}

Tea is a drink made by infusing the leaves of the Camellia Sinensis plant. Tea has its origins in China, more than 3000 years ago. ${ }^{1,2}$ Initially, tea was used as a chewable item with medicinal properties. ${ }^{2}$ Over the centuries, tea expanded worldwide (Fig. 1). Tea commercialization started from China to Mongolia and Tibet. ${ }^{3}$ Through the Buddhist monks, tea was able to spread throughout the rest of Asia. ${ }^{3}$

During the 16th and 17th centuries, tea spread throughout Europe thanks to English, Dutch and Portuguese commercial sailing ships, reaching the New World (America) at the end of the 17 th century. ${ }^{3,4}$

British diplomats gave tea to the Moroccan royalty. However, the Berbers from southern Morocco were those who crossed the Sahara to other cities and started tea trading in Africa. ${ }^{3}$ Tea adopted particular connotations in each new cultural context. ${ }^{3}$

Therefore, this drink has been very popular for centuries ${ }^{1,4}$ due to its pleasant sensory attributes, ${ }^{5-7}$ extensive health benefits $^{2,8}$ and socio-cultural characteristics. ${ }^{5,6}$ Actually, nowa-

\footnotetext{
${ }^{a}$ Departamento de Nutrición y Bromatología, Instituo de Nutrición Y Tecnología de los Alimentos, Centro de Investigación BIomédica, Universidad de Granada, Granada, Spain.E-mail: jarufian@ugr.es; Fax: +34 9582495 77; Tel: +34958242841

${ }^{b}$ Department of Biochemistry and Molecular Biology, Boonshoft School of Medicine, Wright State University, Dayton, $\mathrm{OH}$, USA

${ }^{c}$ Instituto de Investigación Biosanitaria ibs. GRANADA, Universidad de Granada, Granada, Spain
}

days it is one of the most consumed drinks worldwide. ${ }^{4,5}$ Green tea is more commonly consumed in Asian countries while black tea is more popular in Western countries. ${ }^{2}$ Recently, a new generation of consumers has emerged, which has promoted tea drinking habits and generated a growth in market value, ${ }^{7,9}$ even spreading the consumption of cold tea. ${ }^{10}$

\subsection{Tea varieties}

Tea is an intensive monoculture that grows best in areas with subtropical or mountainous precipitation and slightly acidic soils. ${ }^{2}$ It is usually picked as a young shoot but varies according to the variety of tea. ${ }^{2}$

Currently, most of the world's tea is produced in China, but it is grown in at least 30 countries around the world, including India, Sri Lanka, Kenya, Turkey, Viet Nam and Indonesia ${ }^{2}$ (Fig. 1). One example is that white tea production doubled from 2010 to $2017 .^{11}$

After harvest, there are different techniques to process the tea leaves. Depending on the process, six varieties can be clearly differentiated $^{12}$ (Fig. 2). These processing techniques date back thousands of years. ${ }^{12}$ The main processes to which they are subjected are listed in Table 1 . The six types of teas are classified according to the fermentation/oxidation process as this process gives each type unique chemical and sensory characteristics. ${ }^{7,12}$

The main tea types are green tea, white tea, yellow tea, oolong tea, black tea and dark tea. Green tea is produced from fresh leaves that are steamed at high temperatures, thus inactivating oxidative enzymes but leaving the polyphenol content intact. $^{2,13}$ White tea is made from new shoots and young 


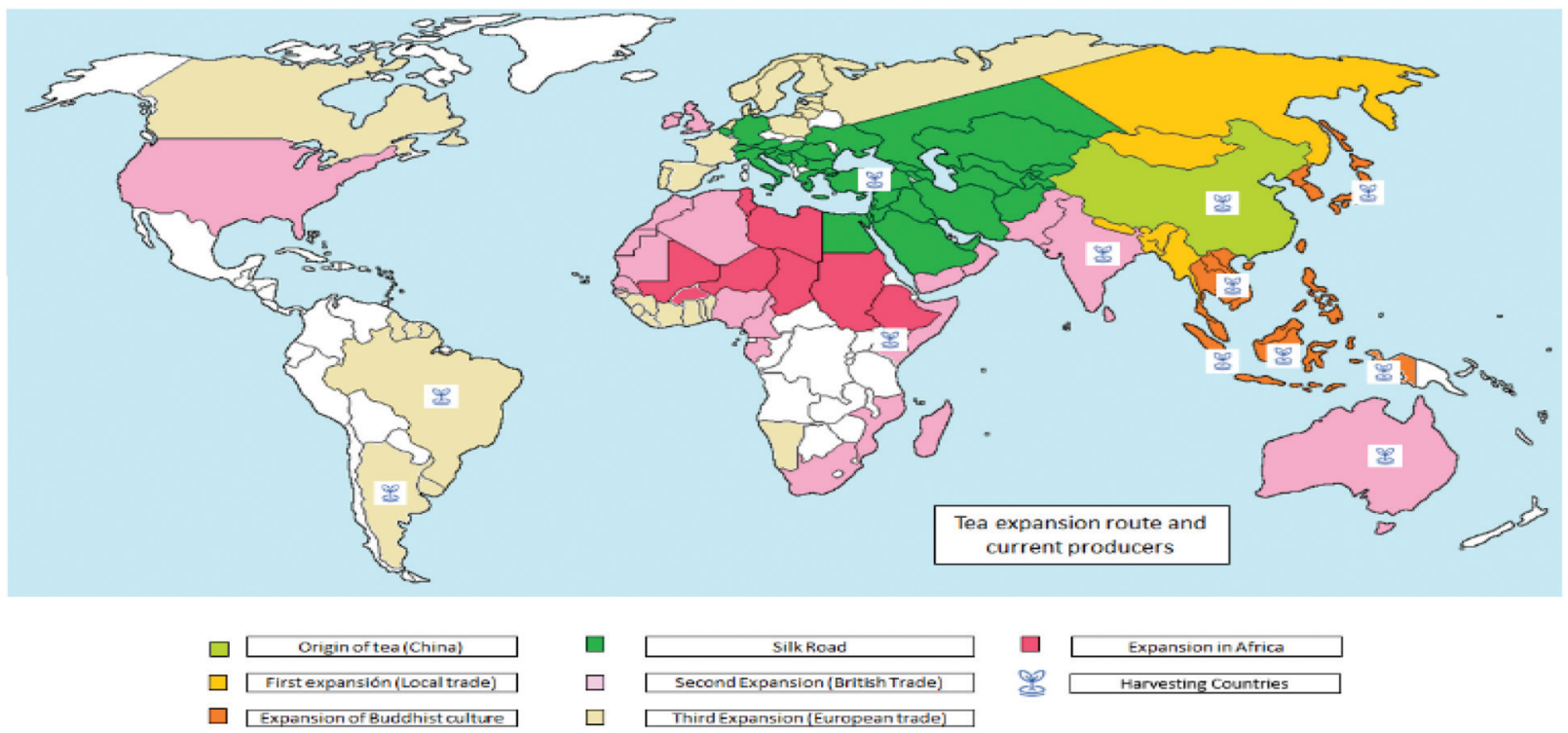

Fig. 1 Tea expansion around the world along history and main tea producing countries nowadays. Tea commercialization started from China, spread throughout the rest of Asia, Europe, America and then Africa. ${ }^{3,4}$

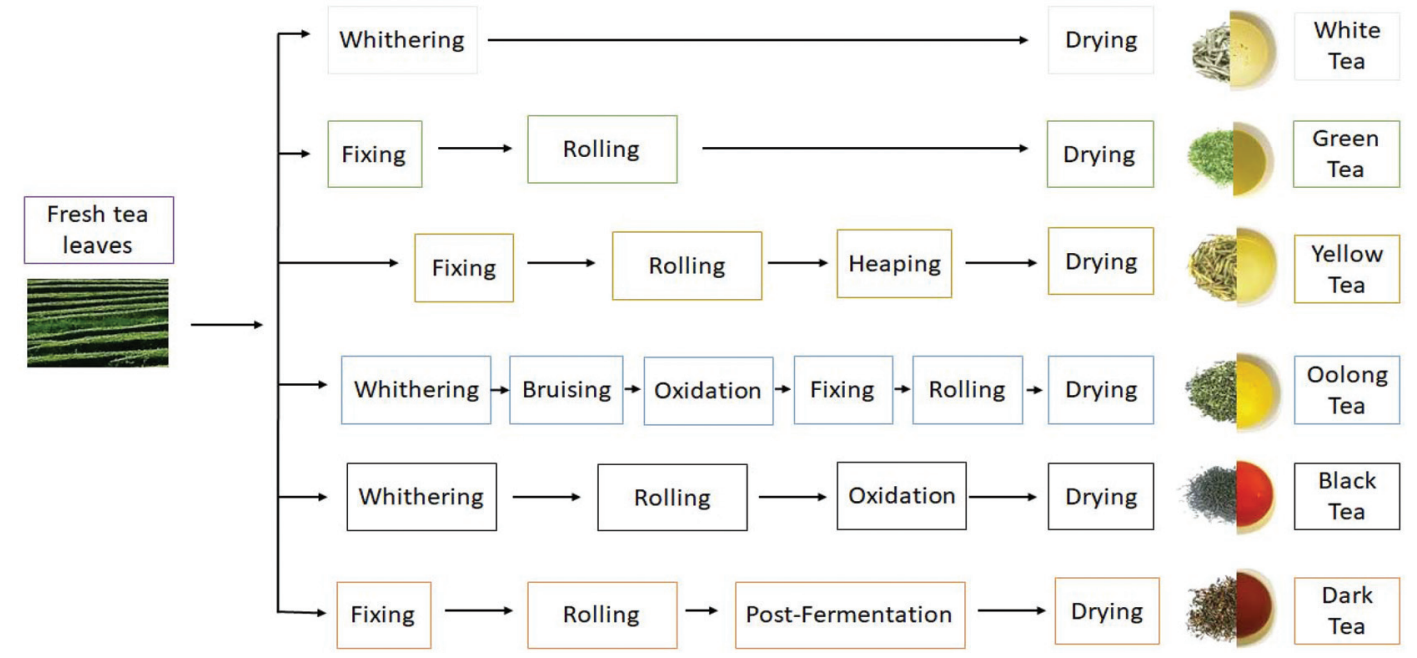

Fig. 2 Tea varieties and processing steps.

leaves ${ }^{6}$ and undergoes the least amount of manufacturing processes, although it has a minimum of $5 \%$ oxidation, retaining high levels of antioxidant compounds..$^{2,7,13,14}$ Yellow and Oolong teas are partially oxidized varieties, $10-20 \%$ and $30-60 \%$, respectively. ${ }^{2,13}$ Black tea can present between 80 and $95 \%$ of oxidation, losing therefore some nutrients, although providing a softer taste. ${ }^{2,13}$ Finally, dark tea undergoes a postfermentation process by exogenous microorganisms, while other teas are only subjected to natural enzyme-induced oxidation. $^{13}$

The last process of any tea is drying, which is carried out at different temperatures depending on the type of tea. ${ }^{21}$ Drying modifies tea composition, especially destroying those thermolabile molecules. ${ }^{21}$ In this sense, the antioxidant capacity and phenolic content, as measured by the Folin-Ciocalteu method, change during drying. ${ }^{21}$ Additionally, some chemical markers have been used to monitor this step for a less damaging procedure. $^{21}$

\subsection{Tea composition}

The composition of tea leaves is complex. Generally it is composed of proteins (15-20\% dry weight), with enzymes (constituting an important fraction) and amino acids such as theanine or 5 - $N$-ethylglutamine, tryptophan, tyrosine, leucine, or lysine. ${ }^{2,4,15}$ Tea leaves also contain vitamins such as vitamin $\mathrm{C}$, $\mathrm{E}$ or $\mathrm{B}$ and trace elements $(\mathrm{Zn}, \mathrm{Mg}$ and $\mathrm{Ca}) \cdot{ }^{10,14}$ In addition, other compounds are also important in tea composition such as different phenolic compounds, highly represented by cate- 
Table 1 Main processes of tea processing

\begin{tabular}{ll}
\hline Production process & Modifications in leaves \\
\hline Withering & Special process where some of the water evaporates, usually due to the effect of the sun \\
Fixing & Process that stops oxidation reactions in leaves due to the application of temperature \\
Rolling & Process for shaping the leaf, making it more workable \\
Drying & Final process by which the remaining moisture is removed \\
Heaping & Process where the leaves are stacked (adding some humidity) \\
Bruising & Process to induce breaks in the leaves \\
Oxidation & Process where endogenous enzymes degrade and transform leaf structures and compounds \\
Post-fermentation & Fermentative process produced by exogenous microorganisms of the leaf, modifying chemical, \\
& nutritional and organoleptic properties
\end{tabular}

chins, methylxanthines, such as caffeine, theobromine and theophylline, ${ }^{2,4}$ or aromatic substances. ${ }^{14,15}$ However, there can also be found heavy metals or pesticides, which are harmful to humans and should be taken into account. ${ }^{14}$

Although the quality of commercial tea is influenced by various processing methods, catechins, caffeine and amino acids in fresh tea leaves are the three most important determinants. ${ }^{15}$ Tea catechins include gallocatechin (GC), epicatechin (EC), epigallocatechin (EGC), epicatechin gallate (ECG), gallocatechin gallate (GCG) and epigallocatechin gallate (EGCG) ${ }^{12}$ with the latter being the most studied. ${ }^{16}$ Also theanine, one of the most abundant amino acids found in tea, has recently attracted great interest. ${ }^{17}$

Catechins are the main phenolic compounds in tea infusions. ${ }^{5}$ Catechins are metabolized in vivo by various metabolic transformations, with the liver and gut being their main metabolic organs. ${ }^{16}$ Their metabolites are released into the circulatory system and distributed to different organs and tissues where they exert their main actions. ${ }^{16}$ EGCG is that with the highest number of phenolic hydroxyl groups, so it is the one with the highest antioxidant activity and, therefore, the one that could present the highest bioactivity. ${ }^{5}$

\subsection{Variations in tea composition}

Tea flavour and bioactivity are mainly dominated by non-volatile metabolites retained in the leaf until it is infused. ${ }^{2,7,12}$ The presence of these bioactive molecules depends on several factors. On the one hand, it is influenced by the industrial processes applied to fresh leaves ${ }^{2,7,13,14}$ and by the geoclimatic conditions $^{6,15}$ under which the plant grows. On the other hand, the preparation of the drink by infusion becomes another critical point ${ }^{9}$ since this process allows the extraction of bioactive compounds from the tea leaves to the drink. ${ }^{18-20}$

The chemical composition of tea leaves depends on the climate, season, region, geography, horticultural methods or the age of the leaf. ${ }^{4}$ Altitude and latitude also affect the composition of metabolites, mountain crops have showed a higher level of free amino acids while crops in the plains have showed higher concentrations of catechins. ${ }^{15}$ The concentration of catechins in the leaf increases with sunlight exposure. ${ }^{15}$ Amino acids in tea leaves, on the other hand, increase with temperature and rainfall and higher concentrations have been found in crops during spring. ${ }^{15}$ Additionally, both caffeine and catechins are found at higher concentrations in young leaves than in old leaves. ${ }^{15}$ During the industrial processing of fresh leaves into different types of teas, their organoleptic properties and composition are affected. ${ }^{21}$ During withering, the levels of most amino acids and theaflavins increase significantly, while the levels of catechins decrease. ${ }^{7}$ During oxidation, catechins and other polyphenols undergo reactions catalysed by polyphenol oxidases to form theaflavins. ${ }^{7}$ Therefore, there is a relationship between the content of these compounds and the oxidation levels of tea leaves. ${ }^{4,13,16}$ This reaction also increases free amino acid levels. ${ }^{4,5}$ Green and white teas are the least oxidized varieties and the varieties that preserve more compounds such as phenolic compounds (mainly flavonoids). ${ }^{4,13}$ Oolong and yellow teas undergo mild oxidation processes, which make them softer in taste and therefore more acceptable to some consumers. ${ }^{13}$ Alterations in the amino acids also contribute to the "umami taste" of tea. ${ }^{4}$ The levels of methylxanthines are also affected by processing, especially theobromine. ${ }^{12,13}$ While caffeine levels are relatively stable among the six types of teas, theophylline and theobromine increase markedly perhaps as a result of microbial fermentation. ${ }^{12}$

Post-fermentation is another important stage during the elaboration of tea because it is able to increase the level of some amino acids, such as valine, suggesting the possibility that these amino acids are products of microbial fermentation. ${ }^{4}$ Emerging techniques are currently being developed to further conserve bioactive compounds during tea leave processing. An example is the superfine grinding technique. ${ }^{10}$ This is a processing superfine grinding technique that consists of increasing the rupture of the cell walls at low temperature with the subsequent surface increase of tea particles, which makes them better preserve their bioactive compounds. ${ }^{10}$

Finally, time and temperature during tea infusion are critical for the extraction of bioactive compounds. This process affects not only the drink's antioxidant capacity, but also its organoleptic characteristics. ${ }^{6}$

The methods of tea infusion vary all over the world and depend on the different varieties of tea. For example, though temperatures usually range from 70 to $100{ }^{\circ} \mathrm{C}$, infusion methods have been developed at room temperature or under cold conditions. ${ }^{4,9}$ Infusion time also varies from 10 seconds to 10 minutes. ${ }^{4,6}$ For example, some countries often perform 
several extractions of the same leaves and even drink infusions in milk. ${ }^{4}$ Tea infusions at $100{ }^{\circ} \mathrm{C}$ were found to be optimal for extracting catechins and caffeine. ${ }^{18,19}$ However, the effect of temperature on theanine, free amino acids and water extracts varied, being better with cold water. ${ }^{18,19}$ Thus, we can observe that temperature and different extraction methods are capable of modifying not only bioactive compounds but also their antioxidant activity. ${ }^{4,18}$ A prolonged cold water extraction showed higher antioxidant capacity compared to other extraction methods in green teas. ${ }^{4}$ However, black tea showed its highest antioxidant capacity with hot water extraction. ${ }^{4}$ Studies show that white tea exhibited greater antioxidant capacity when the leaves were infused for 2 hours at room temperature, suggesting that cold infusions may be a good alternative for maintaining the nutritional and functional properties of tea. ${ }^{4,18,19}$

The aim of this review was to provide an overview of tea (with emphasis in green and white teas) and its latest research. After a general introduction, we have focused on its beneficial effects, adverse effects and new approaches to the tea and its bioactive compounds.

\section{Beneficial effects of tea and related bioactive compounds}

Strong evidence is growing to support the preventive and therapeutic effects of tea on different diseases. ${ }^{5}$ Green and white teas are those with the highest concentration of bioactive compounds, so that these teas also have the greatest protective effects on health. ${ }^{1,6}$ There is a broad acceptance that such effects can be obtained with moderate tea consumption (3-5 cups per day; $250 \mathrm{ml}$ per cup). ${ }^{1,6}$ For this reason, this review focuses on the latest studies carried out in recent years (2017-2020), focusing more on the healthy properties of white and green teas, their extracts and their main bioactive compounds (Table 2).

We have analysed the literature from the Web of Science database with the keywords "Camellia Sinensis" AND "Health". The metadata were staggered and analysed with VOSviewer version 1.6.16 by using co-occurrence and keywords. From the more than 10000 keywords obtained, the 80 most common keywords were selected (Fig. 3).

\subsection{Antioxidant capacity}

Antioxidant capacity is one of the main properties of tea. ${ }^{101}$ Many diseases are associated with oxidative damage caused by reactive oxygen species (ROS). ${ }^{16,22-24}$ Some tea compounds, especially polyphenols, have a high antioxidant capacity. ${ }^{16,22-24}$ In this sense, different pathways associated with the antioxidant properties of tea phenolic compounds have been identified. ${ }^{24}$ Their chemical structure allows polyphenols to react with ROS, neutralizing them and avoiding their accumulation in the organism. ${ }^{16,24}$ It has been shown that compounds such as tea catechins regulate the expression of certain endogenous antioxidant enzymes such as superoxide dismutase or glutathione $S$-transferase, modulating their activity. ${ }^{16,24}$ Results in animal experiments confirm that catechins can increase enzymatic activity and ensure continuous elimination of ROS. ${ }^{24}$ Phenolic compounds are also able to modulate the activity of certain metabolic pathways and thus reduce the production of oxygen-free radicals. ${ }^{16,22-24}$ A clear example is the chelation of certain minerals such as iron or calcium, which inhibits their action as catalysts for some oxidation reactions. ${ }^{24}$ Another example is how some tea catechins are able to reduce free radicals in lipids and stimulate $\beta$-oxidation. ${ }^{22,24}$ In rodents, tea polyphenols have a synergistic effect with some vitamins and increased serum antioxidant capacity. $^{24}$

Theanine is another bioactive compound in tea that has shown antioxidative effects in mitigating ROS induced damage. ${ }^{25}$ Theanine also tends to reduce the toxic side effects stimulated by certain drugs, relieves lipid peroxidation levels and modulates the enzymatic activity of drug-driven glutathione peroxidase. ${ }^{23,25}$ In animals, it has been described that supplementation with green tea increases the enzyme glutathione $S$-transferase, which helps the detoxification of xenobiotics. ${ }^{25}$ Green tea and its extracts are able to reduce toxicinduced oxidative stress and even show promising detoxification effects. ${ }^{16}$ The antioxidant capacity of green tea phenolic compounds exerts protective effects against some xenobiotics such as mycotoxins, heavy metals, pesticides or smokingderived compounds. ${ }^{16}$

In summary, there are many possible mechanisms by which tea and its bioactive compounds are able to exhibit their antioxidant activity. Many of these mechanisms are crucial in action on different diseases.

\subsection{Anti-inflammatory activity}

Inflammation is an immune system response to damage and is linked to a multitude of pathologies and disorders. Green tea consumption has been shown to significantly reduce serum levels of different inflammatory markers such as C-reactive protein. ${ }^{26}$ Moreover, certain components of green tea (such as catechins) can increase the production of antiinflammatory cytokines (i.e. IL-10), regulating also the synthesis and signalling of IL-6 and decreasing pro-inflammatory cytokines such as IL-1 $\beta$ and TNF- $\alpha .^{22,26-30}$

According to a meta-analysis of randomized clinical trials carried out by Haghighatdoost and Hariri, ${ }^{27}$ no significant effect on C-reactive protein was detected. However, a significant decrease in the levels of TNF- $\alpha$ was observed. They attributed these results to a low bioavailability of tea bioactive compounds after intake. In addition, these authors stated that tea anti-inflammatory effects would be better observed in a severe inflammation. ${ }^{27}$ A study with people suffering from metabolic syndrome $v s$. healthy people receiving a green tea supplement ( $1 \mathrm{~g}$ day $^{-1} ; 890 \mathrm{mg}$ total catechins, for 28 days) showed a decrease in mRNA expression levels of dependent inflammatory genes. ${ }^{30}$ Green tea catechins reacted to the inflammatory responses and could help reverse the progression of the meta- 
Table 2 Health properties and effects of the different varieties of teas and their bioactive compounds.

\begin{tabular}{|c|c|c|c|}
\hline Health properties & $\begin{array}{l}\text { Varieties of teas and } \\
\text { their bioactive } \\
\text { compounds }\end{array}$ & Effects and mechanisms & Ref. \\
\hline Antioxidant capacity & $\begin{array}{l}\text { Tea } \\
\text { Polyphenols } \\
\text { Catechins } \\
\text { Theanine } \\
\text { Tea + vitamins }\end{array}$ & $\begin{array}{l}\text { - Inhibition of free radicals } \\
\text { - Regulation of the expression and activity of certain antioxidant } \\
\text { enzymes } \\
\text { - Chelation of minerals } \\
\text { - Increase of serum antioxidant capacity } \\
\text { - Increased detoxification of environmental contaminants }\end{array}$ & 16 and $22-25$ \\
\hline Anti-inflammatory activity & $\begin{array}{l}\text { Green tea extract } \\
\text { Catechins } \\
\text { EGCG }\end{array}$ & $\begin{array}{l}\text { - Reduction of inflammatory markers such as C-reactive protein } \\
\text { - Increase of anti-inflammatory cytokines such as IL-10, regulation } \\
\text { of IL-6 and decrease of pro-inflammatory cytokines such as IL-1 } \beta \\
\text { and TNF- } \alpha \\
\text { - Decrease mRNA expression of inflammatory dependent genes } \\
\text { - Improvement of the intestine integrity } \\
\text { - Decrease of immunoreactive nitrotyrosine and the overregulation } \\
\text { of the intercellular adhesion molecule- } 1\end{array}$ & 22 and $26-30$ \\
\hline Lipolysis and obesity & 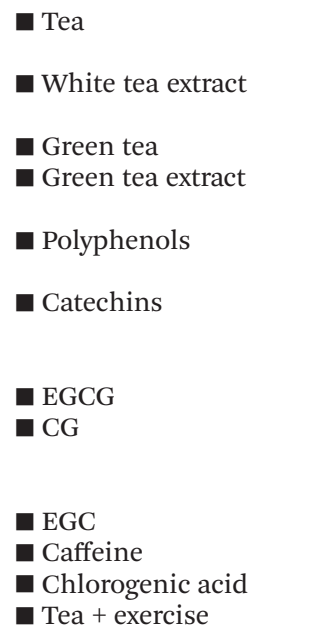 & $\begin{array}{l}\text { - Improvement of lipid metabolism, reduction of apolipoprotein B, } \\
\text { modulation of } \beta \text {-oxidation of fatty acids and activation of AMPK } \\
\text { - Modulation of cholesterol and triglyceride levels by reducing the } \\
\text { production of low-density lipoproteins } \\
\text { - Increased GLUT4mRNA expression } \\
\text { - Attenuation of endothelial dysfunction induced by low-density } \\
\text { lipoproteins oxidised through Jagged-1/Notch } \\
\text { - Regulation of digestive enzyme activity such as gastric and } \\
\text { pancreatic lipases } \\
\text { - Prevention of bile acid reabsorption from the small intestine, } \\
\text { modulation of the synthesis of bile acids and increase of the faecal } \\
\text { excretion of cholesterol } \\
\text { - Decrease of leptin levels } \\
\text { - Stimulation of energy expenditure and thermogenesis by } \\
\text { increasing mRNA levels of thermogenesis genes such as Ucp1 and } \\
\text { Ucp2 } \\
\text { - Reduction of body weight and body mass index } \\
\text { - Decrease of waist/hip ratio, visceral fat and body fat }\end{array}$ & 22 and $31-41$ \\
\hline $\begin{array}{l}\text { Hypertension and } \\
\text { cardiovascular diseases }\end{array}$ & 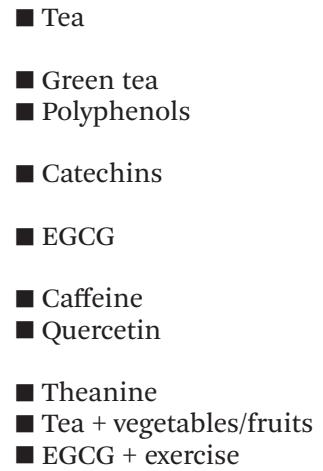 & $\begin{array}{l}\text { - Inversely related to the risk of cardiovascular disease and } \\
\text { prevalence of coronary artery disease } \\
\text { - Reduction of the ischemic stroke risk } \\
\text { - Reduction of systolic and diastolic blood pressure and } \\
\text { antihypertensive activity } \\
\text { - Reduction of vascular inflammation by improving endothelial } \\
\text { dysfunction and vascular function } \\
\text { - Increase of nitric oxide plasmatic concentration and inhibition } \\
\text { of pro-inflammatory cytokines and platelet aggregation } \\
\text { - Improvement of endothelial dysfunction and blood flow } \\
\text { - Improvement of blood vessel homeostasis and regulation of the } \\
\text { renin-angiotensin-aldosterone system }\end{array}$ & $\begin{array}{l}22,31,35 \\
\text { and } 42-45\end{array}$ \\
\hline $\begin{array}{l}\text { Effect on glycemic control and } \\
\text { diabetes }\end{array}$ & 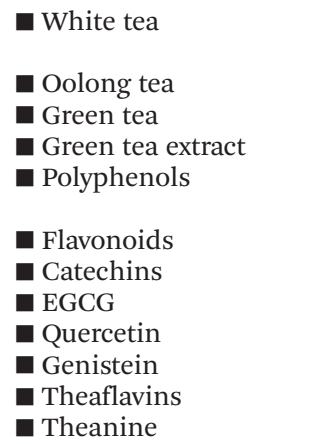 & $\begin{array}{l}\text { - Significant reduction in blood glucose, improvement in glucose } \\
\text { intolerance and increased sensitivity to insulin } \\
\text { - Protection of } \beta \text { cells on the Langerhans islets } \\
\text { - Inhibition of inflammatory factors and reduction of ROS } \\
\text { - Modulation of gene expression of related enzymes } \\
\text { - Suppression of glucose intestinal absorption by inhibiting } \\
\text { enzyme activity } \\
\text { - Inhibition of the insulin tyrosine kinase receptor }\end{array}$ & $\begin{array}{l}22,25,31 \\
\text { and } 45-50\end{array}$ \\
\hline
\end{tabular}


Table 2 (Contd.)

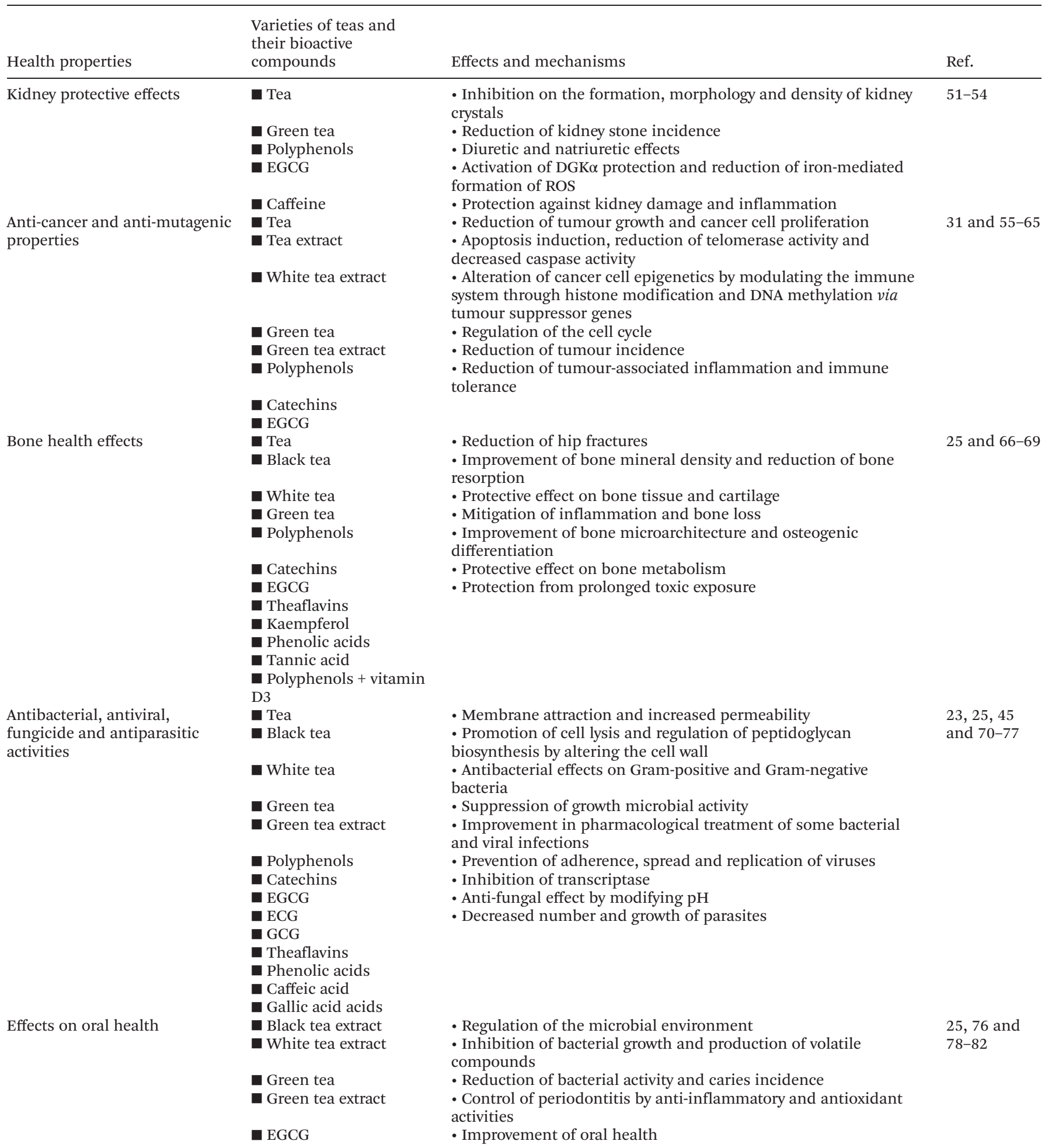


Table 2 (Contd.)

\begin{tabular}{|c|c|c|c|}
\hline Health properties & $\begin{array}{l}\text { Varieties of teas and } \\
\text { their bioactive } \\
\text { compounds }\end{array}$ & Effects and mechanisms & Ref. \\
\hline $\begin{array}{l}\text { Effects on dermatological } \\
\text { health and antiallergic effect }\end{array}$ & $\begin{array}{l}\text { Tea } \\
\text { a Green tea } \\
\text { Green tea extract } \\
\text { a Polyphenols } \\
\text { a Catechins } \\
\text { EGCG }\end{array}$ & $\begin{array}{l}\text { - Reduction of some immunoglobulin, histamine and pro- } \\
\text { inflammatory cytokines } \\
\text { - Alternative treatment of rhinitis } \\
\text { - Reduction of skin desquamation and psoriasis in topical } \\
\text { application } \\
\text { - Modulation of collagenase and elastase activity helping to } \\
\text { maintain skin elasticity } \\
\text { - Reduction in the number of inflammatory lesions } \\
\text { - Potential of anti-haemorrhagic applications and promotion of } \\
\text { wound healing }\end{array}$ & $\begin{array}{l}25,77,83 \\
\text { and } 84\end{array}$ \\
\hline $\begin{array}{l}\text { Effects on stress and brain } \\
\text { function }\end{array}$ & $\begin{array}{l}\text { Tea } \\
\text { White tea } \\
\text { Green tea } \\
\text { Green tea extract } \\
\text { C Catechins } \\
\text { EGCG } \\
\text { ECG } \\
\text { Theanine } \\
\text { G Caffeine } \\
\text { a Gallic acid } \\
\text { - Pyrogallol }\end{array}$ & $\begin{array}{l}\text { - Relaxing and anxiety-reducing effect } \\
\text { - Reduced the depression risk } \\
\text { - Improvement of mental and sleep health } \\
\text { - Reduction of cognitive impairment } \\
\text { - Activation of } \alpha, \beta \text { and } \theta \text { wave production in the front and central } \\
\text { parts of the brain } \\
\text { - Modulation of GABA } \\
\text { - Neuroprotective effects against neural injury, Huntington's } \\
\text { disease and amyotrophic lateral sclerosis } \\
\text { - Improvement of memory in Parkinson's disease } \\
\text { - Suppression of amyloid plaque formation, } \\
\text { immunohistochemical alteration and oxidative damage } \\
\text { - Neuronal protections by inhibition of ROS generation and A } \beta \\
\text { fibrils formation in the brain tissue } \\
\text { - Significant competitive inhibition of acetylcholinesterase and } \\
\text { modulation of acetylcholine levels } \\
\text { - Reduction of brain swelling and improvement of endothelial } \\
\text { function }\end{array}$ & $\begin{array}{l}17,23,25,29 \\
\text { and } 85-94\end{array}$ \\
\hline Lung health effects & $\begin{array}{l}\text { Tea } \\
\text { EGCG }\end{array}$ & $\begin{array}{l}\text { - Improvement of histopathological injuries } \\
\text { - Reduction of pro-inflammatory markers } \\
\text { - Improvement of lung regeneration capacity }\end{array}$ & 95 \\
\hline Effects on fertility & $\begin{array}{l}\text { - Green tea } \\
\text { - EGCG }\end{array}$ & $\begin{array}{l}\text { - Improvement of fertility rate } \\
\text { - Stimulation and regulation of hormones responsible of the } \\
\text { menstrual cycle } \\
\text { - Modulation of progesterone and oestrogen levels } \\
\text { - Reduction of DNA fragmentation and improvement of sperm } \\
\text { motility and viability }\end{array}$ & 96 \\
\hline
\end{tabular}

bolic syndrome. However, these authors acknowledge that longer term interventions are needed. ${ }^{30}$

Inflammation of the intestinal epithelial barrier is important in diseases such as inflammatory bowel disease or Crohn's disorder. Rodent models have shown that catechinrich green tea extract improves the integrity of the intestinal barrier. This generates a modulation in the translocation of endotoxins derived from the intestine, and their consequent pro-inflammatory responses. ${ }^{28-30}$ EGCG treatment significantly increased antioxidant capacity and reduced the signs of related colitis, as well as mitigating less severe symptoms. ${ }^{28-30}$ Green tea extract also reduces the entry of immunoreactive nitrotyrosine into the colon and reduces the over-regulation of intercellular adhesion molecule 1 (ICAM-1). ${ }^{28}$ In summary, tea polyphenols have shown a great protective effect against several chronic inflammatory disorders. ${ }^{28-30}$

\subsection{Effects on lipolysis and obesity}

Obesity is a chronic multifactorial disease characterized by an excessive accumulation of fat. ${ }^{22}$ The anti-obesogenic effects of different types of teas and their bioactive compounds have been described at anthropometric and biochemical levels. $^{22,31-41}$ According to the latest in vitro and animal studies, the main effects described were to decrease lipid absorption and to increase fat oxidation, thus reducing triglyceride, cholesterol and leptin and to stimulate energy expenditure..$^{22,32-36}$ In epidemiological studies the main effects described were a reduction in body weight, variation of the body mass index, a decrease of waist/hip ratio, and a reduction of visceral and body fat. ${ }^{22,32,37-41}$

White tea extracts are able to modulate the metabolic syndrome, particularly by improving lipid metabolism. ${ }^{33}$ These 


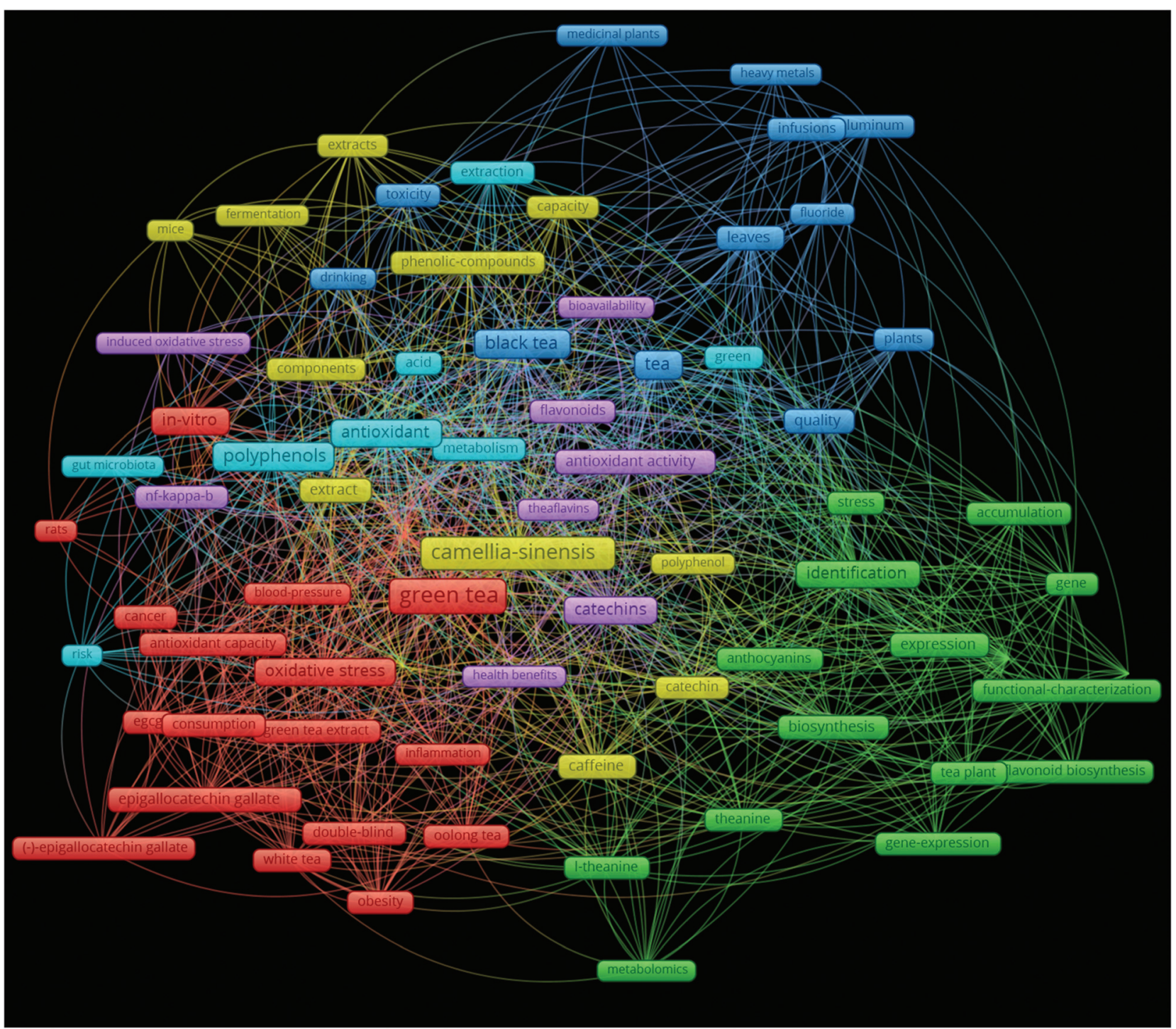

Fig. 3 Main keywords related to the search terms "Camellia sinensis" AND "Health" analysed with VOSviewer.

extracts significantly reduced apolipoprotein B and modulated cholesterol and triglyceride levels by reducing the production of low-density lipoproteins. They also reduced significantly the accumulation of intracellular triglycerides. ${ }^{33}$

Green tea is the most studied variety of tea regarding its anti-obesogenic effects. ${ }^{22,32,35,37,38}$ The effects vary according to the dose, the type of extract and the duration of the intervention, so the effectiveness depends on the dose-response ratio. $^{22,37}$ In a cross-sectional study of 232 middle-aged Japanese women, daily intake of green tea was inversely associated with a high body mass index. ${ }^{38}$ According to Lin et al. a green tea dose of $<500 \mathrm{mg}$ day $^{-1}$ for 12 weeks was enough to improve body weight and body mass index, specifically for periods longer than 12 weeks at a dose $<800 \mathrm{mg}$ day ${ }^{-1} \cdot{ }^{38}$ Furthermore, it has been described that subjects who habitually consumed tea at around $400 \mathrm{ml} \mathrm{day}^{-1}$ for 10 years were associated with a lower percentage of body fat and a decreased waist-to-hip ratio. ${ }^{22,37}$ Although protective effects against hyperlipidaemia were described, no effects were observed on high-density lipoproteins, while modifications of low-density lipoprotein and triglyceride levels were obtained. ${ }^{22,35}$ Another mechanism described is the effect on oxidative stress by inducing antioxidant effects in adipose tissue. ${ }^{22}$ In addition, it has also been reported that tea inhibits intestinal lipid absorption by interfering with the formation of micelles. ${ }^{35}$

Tea phenolic compounds appear to play a major role in tea anti-obesogenic effects. Some studies observed that obese rats fed with green tea polyphenols have a repression of lipogenesis in adipose tissue and an activation of AMPK; this caused an increase in GLUT4 mRNA expression and reduced plasma lipid concentrations, stimulating also fatty acid oxidation. ${ }^{22,34}$ In another study, a reduction in the body mass index of Japanese women was described due to the synergistic effect of caffeine and chlorogenic acid. ${ }^{38}$ Caffeine in green tea has effects on 
weight loss at doses $>300 \mathrm{mg}$ day $^{-1},{ }^{32}$ modifying also thermogenesis and the metabolism of white adipose tissue. ${ }^{22,31}$ Both in vitro and animal experiments have shown that green tea catechins can modulate lipid homeostasis by reducing the levels of plasma triglycerides, low-density lipoproteins and total cholesterol. ${ }^{22,35}$ Catechins suppressed the synthesis of fatty acids and down-regulated $\beta$-oxidation. ${ }^{22}$ In rats, EGCG has been found to influence the expression of acetyl coenzyme A carboxylase-1 and reduce the accumulation of fatty tissue. ${ }^{22}$ Additionally, EGCG may attenuate endothelial dysfunction induced by oxidized low-density lipoprotein through Jagged-1/ Notch. ${ }^{35}$ Other catechins, such as CG and EGC, attenuated the accumulation of lipids around $50 \% .^{22}$ Green tea catechins reduce cholesterol concentrations and increase faecal excretion in animals. ${ }^{36}$ Catechins also reduced the activity of digestive lipase, gastric lipase and pancreatic lipase by altering the emulsification process and consequently reduced fat digestion-absorption. ${ }^{22}$ In addition, tea catechins prevent the reabsorption of bile acids in the small intestine, influencing (i.e. increasing) the synthesis of bile acids. ${ }^{22}$ Luo et al. showed how EGCG and ECG from white tea extracts contributed to the regulation of genes related to cholesterol metabolism. ${ }^{34}$ EGCG fed to mice induced an increase of body temperature by improving mRNA levels of thermogenesis genes such as Ucp1 and Ucp $2{ }^{22}$ In addition, effects on the reduction of leptin in rats treated with EGCG have been described. ${ }^{22}$ A double-blind study in healthy Japanese men confirmed that an intake of $690 \mathrm{mg}$ of tea catechins often significantly reduced body weight and fat mass after 12 weeks of intervention. ${ }^{22}$ According to a meta-analysis carried out by Sultane and Cambaza there was a direct relationship between catechin concentration and body mass index reduction, body weight and waist/hip ratio reduction. ${ }^{39}$ Most of the in vitro studies suggest clear anti-obesogenic effects, but epidemiological studies show high heterogeneity.

Ethnicity, initial body mass index and age combined with a short duration and small sample size make it difficult to establish definitive relationships between the beneficial effects of tea consumption and its direct effects on obesity. ${ }^{22,32,35,37}$ Therefore, it is suggested to consume tea together with a balanced diet and physical exercise. ${ }^{32,37-39}$ Some studies have evaluated the effect of tea consumption and its relation to physical exercise. ${ }^{39-41}$ Bagheri et al. showed that green tea extracts improve exercise-induced body composition by further reducing exercise-induced changes in weight, body mass index, waist/hip ratio and body fat. ${ }^{41}$ They performed an intervention with an 8-week training program that included training 3 times a week along with a green tea capsule with $500 \mathrm{mg} \mathrm{day}{ }^{-1}$. The results showed improvements related to body composition and inflammation, as well as increased serum adiponectin concentrations. ${ }^{41}$ These results give a great perspective to therapies that combine daily tea consumption with an exercise routine to fight obesity.

\subsection{Effects on hypertension and cardiovascular diseases}

Cardiovascular diseases (CVD) are a heterogeneous group of pathologies affecting the circulatory system. Observational studies have indicated that green tea intake is inversely related to CVD risk. ${ }^{35}$ In a large retrospective study in Japanese people, consumption of 3-4 cups of tea reduced the risk of ischemic stroke. ${ }^{22}$ In another study, a group of 612 participants in Tokyo, Japan, underwent coronary angiography and dietary assessment. Increased consumption of green tea was significantly associated inversely with the prevalence of coronary artery disease. Those patients who drank $>3$ cups per $d$ had a lower prevalence than those who had an intake of $<1$ cup per day. This low prevalence was reported also in subgroups with high fruit and vegetable intake. ${ }^{42}$ According to a meta-analysis by Xu et al., in which 24 studies involving 1697 subjects were analysed, the consumption of green tea significantly reduced systolic and diastolic blood pressure. They proposed as possible mechanisms a decreased oxidative stress and a reduction of vascular inflammation improving endothelial dysfunction. ${ }^{44}$

There are several compounds that could mediate tea effects over CVD. Phenolic compounds have antioxidant effects on the cardiovascular system. ${ }^{31}$ Green tea catechins increase plasma concentration of nitric oxide, which can inhibit pro-inflammatory cytokines and platelet aggregation and lead to improvement of the endothelial dysfunction and blood flow. ${ }^{43,44}$ Particularly, EGCG showed a strong antihypertensive activity $^{31,43}$ and a dose-dependent effect on vasodilation in rodents. In addition, EGCG improves localized blood flow after an endurance exercise session, although further research is required. ${ }^{44}$ On the other hand, caffeine regulates the homeostasis of the blood vessels. ${ }^{31,43}$ Quercetin and theanine reduce blood pressure in animals and humans and therefore reduce the risk of cardiovascular disease. Quercetin reduces also oxidative stress and acts on the renin-angiotensin-aldosterone system by improving vascular function. ${ }^{45}$ Despite evidence of possible beneficial effects, these only show slight associations in epidemiological studies and therefore more studies are needed. ${ }^{22,42,43}$

\subsection{Effects on glycaemic control and diabetes}

Diabetes mellitus is a disorder in which blood glucose is excessively high and is related to insulin resistance and insufficient insulin secretion. ${ }^{25}$ There are several studies that highlight the effects of green and white teas and their bioactive compounds both in in vitro and in animal studies. ${ }^{2,25,45-47}$ The research carried out by Xia et al. showed a significant reduction in blood glucose and an improvement in glucose intolerance in mice after drinking white tea. In addition, a protective activity of the $\beta$-cells in the Langerhans islets against oxidative and inflammatory damage was observed. ${ }^{48}$ This confirms a previous study with pre-diabetic rats which drank white tea for two months, finding increased sensitivity to insulin. ${ }^{45}$ Therefore, white tea has clear potential for blood glucose control and to protect against diabetes. ${ }^{45,47}$

Green tea effects on blood glucose levels are attributed to altered insulin tolerance in peripheral tissues such as skeletal muscles and adipocytes. ${ }^{25}$ Diabetic mice treated with green tea polyphenols for 15 days showed a $44 \%$ reduction in serum glucose. ${ }^{25}$ In another study, Wistar rats were treated with green tea for eight weeks. Although a poor hypoglycaemic effect was 
observed, it was able to reduce diabetic complications by inhibiting inflammatory factors and reducing ROS. ${ }^{46}$ EGCG supplementation has also showed to improve glucose tolerance and to prevent the destruction of the Langerhans islets, modulate gene expression of relevant enzymes ${ }^{25}$ and reduce serum glucose levels. ${ }^{45}$ Tea flavonoids, on the other hand, can suppress the intestinal absorption of glucose by inhibiting the activity of $\alpha$-glucosidase and stimulating the glucose transporter 4 (GLUT4) by mediating glucose absorption and increasing insulin sensitivity. ${ }^{46}$ In addition, green tea quercetin and genistein inhibited the activity of the insulin receptor tyrosine kinase IRS-1, IRS-2. ${ }^{22}$ Other in vitro studies in rats show that catechins and theaflavins help prevent hyperglycaemia by inhibiting $\beta$-cell damage and increasing insulin activity. ${ }^{25,45}$

Different epidemiological studies showed that green tea can reduce insulin resistance and improve glycaemic control. However, there was insufficient evidence for these effects. ${ }^{31,48-50}$ In short-term trials, green tea supplementation significantly reduced fasting glucose, but had no significant effect on fasting insulin. ${ }^{50}$ A systematic review by Yu et al. ${ }^{49}$ assessed the effect of green tea and green tea extracts on insulin resistance and glycaemic control. They found that the extracts were more convenient and acceptable to participants than drinking due to taste issues. ${ }^{4}$ In two large-scale population cohorts of Chinese men and women, researchers observed a positive, dose-response association between green tea consumption and a decreased risk of type 2 diabetes. ${ }^{49}$ However, another study carried out in Shanghai (China) warned of the opposite effect: green tea and oolong tea drinkers were at an increased risk of type 2 diabetes. They pointed out that tea drinkers were smokers and drank alcohol more often, were less likely to exercise and also had a higher calorie diet. $^{49}$ Due to these results, more long-term trials are needed to evaluate the effects of supplementation with tea or its bioactive compounds on diabetes and glycaemic control in humans.

\subsection{Kidney protective effects}

Lithiasis or kidney stone formation happens frequently and occurs when salts in urine crystallize. ${ }^{51}$ In vitro studies describe how different types of teas have a significant positive action on the morphology, density and size of the crystals, green tea being the type of tea with the best results. ${ }^{51}$ Two large epidemiological studies suggested that regular tea intake reduces the risk of kidney stone incidence by $13 \%$ and $22 \%$ in women and men, respectively. ${ }^{52}$ According to this study, regular consumption of tea may reduce the risk of kidney stones in a dose-response effect. ${ }^{52}$

Although green tea also contains oxalate, a potential source of crystals, a rat model gave surprising results that supplementation with green tea in drinking water could reduce the amount of crystals deposited within the kidneys. ${ }^{53}$ Some of the responsible mechanisms of a decreased lithiasis risk are the increased fluid intake, the diuretic and natriuretic effect of caffeine and the antioxidant and anti-inflammatory properties of polyphenols. ${ }^{51,52}$
Recently, tea EGCG has been studied for its possible use in the prevention of several kidney diseases, such as acute kidney injury or diabetic nephropathy. So far, it has been reported that green tea EGCG improves albuminuria in diabetic nephropathy in a human trial. The main mechanism involved the activation of DGK $\alpha$, so that protecting kidney activity. ${ }^{54}$ It has been shown that EGCG could act also as an iron chelator, resulting in a decreased ROS production and subsequent protection against kidney damage. ${ }^{53}$ Finally, almost all studies on kidney diseases have been conducted in cells or animal culture models. Further clinical trials are needed to provide conclusive evidence of the protective effects on the kidneys. ${ }^{53}$

\subsection{Anti-cancer and anti-mutagenic properties}

Anti-cancer effects of tea have been the focus of much research in recent years. ${ }^{31,55-65}$ Polyphenols in tea play an important role in the prevention and control of cancer progression due to their different properties. ${ }^{55,56}$ The mechanisms studied are generally based on antioxidant activity, regulation of the cell cycle, modulation of the immune system and epigenetic control. ${ }^{57,60,63}$ In general, tea polyphenols suppress tumour growth and cancer cell proliferation, ${ }^{55,56}$ while also possessing proapoptotic ${ }^{31,55}$ and chemopreventive effects. ${ }^{56}$ According to in vitro studies, several mechanisms for the anti-cancer effects of tea catechins have been observed. ${ }^{57,59,60,63}$ Shirakami and Shimizu $^{64}$ showed the effect of EGCG in reducing telomerase and caspase activities. Additionally, ECGC also indicates the possibility of altering the epigenetic signals in cancer cells through histone modification and DNA methylation. ${ }^{63}$ On the other hand, the same authors acknowledged that the prooxidant activity of green tea polyphenols could induce apoptosis and inhibit the growth of cancer cells. ${ }^{63}$ On the other hand, according to Abe and Inoue (2020), green tea consumption is inversely associated with several forms of cancers such as lung, oral or ovarian, with a risk reduction of around $19 \% .^{31}$ For the other types of cancer, contradictory findings have been observed. ${ }^{31}$ Current research focuses mainly on the effects of tea on colorectal cancer, ${ }^{55-57}$ breast cancer ${ }^{61,62,64}$ and prostate cancer. $^{58-60}$

Colon cancer begins in the large intestine. Some studies describe that green tea consumption can reduce the incidence of colorectal cancer tumors. ${ }^{55,57}$ The data support anti-tumour activity due to histone modification, micro-RNA and DNA methylation. ${ }^{57}$ On the other hand, at optimum doses $(1000 \mathrm{mg}$ $\mathrm{ml}^{-1}$ every $24 \mathrm{~h}$ ) and under in vitro conditions, it was observed that an aqueous extract of white tea played an important role against the HCT-116 cell line of colon cancer and in the regulation of the tumour suppressor gene pathway. ${ }^{55}$ According to Liu et al., extracts of white tea suppressed the growth of BEL 7402 cells. ${ }^{57}$

Breast cancer is one of the most common cancers in women. According to the results of Wang et al. ${ }^{62}$ people who drink green tea are partially protected against breast cancer, especially in the long term at high doses. In a meta-analysis carried out by Yu et al. some evidence from case and control studies suggested a lower breast cancer incidence within the 
population who consumed green tea. However, they also warned about the small number of clinical trials available and the quality of the studies. ${ }^{62}$ On the other hand, another metaanalysis evaluating studies with intakes of more than 5 cups of tea per day showed a potential reduction of breast cancer risk about $15 \%{ }^{64}$

Prostate cancer is one of the most common cancers in men. According to Rogovskii et al. ${ }^{60}$ catechins are among the best known polyphenols in relation to the treatment and prevention of this type of cancer, as they may reduce tumour-associated inflammation and immune tolerance. A prospective, randomized study evaluated the bioavailability of polyphenols and methylation activity in men with prostate cancer, but no significant results were observed. ${ }^{58}$ Miyata et al. presented a summary of the currently published data obtained through in vitro studies, animal experiments and clinical trials. Although in vivo studies had heterogeneous results, in vitro studies showed that some compounds, such as EGCG, suppressed the induction of the cytokine and chemokine genes, being results with great potential. ${ }^{61}$

Finally, Filippini et al. analysed 142 studies looking for an association between green tea consumption and different types of cancer. Their study revealed that the relationship between green tea consumption and cancer risk reduction was inconsistent. ${ }^{66}$ In addition, most of the studies included were in Asian countries that were already high in tea consumption, which limited extrapolation of the results to other populations. ${ }^{65}$ In general, tea extracts in high concentrations and some individual bioactive compounds (such as EGCE) showed very promising in vitro effects. However, the association between consumption of green or white teas and total cancer risk is not clear or conclusive. ${ }^{31,64,65}$ Therefore, more and better designed and longer studies in different types of populations are needed to confirm such positive data.

\subsection{Bone health effects}

Several are the studies that describe the beneficial effects of different varieties of tea on bone health. ${ }^{25,66-69}$ According to Tomaszewska et al. a reduction in the risk of hip fractures was described in regular tea drinkers. ${ }^{67}$ In the same study, a better bone mineral density was achieved by post-menopausal women who drank tea. ${ }^{66}$ Although the effect is mostly described for green tea, white tea exerted the greatest protective effect on bone tissue and cartilage ${ }^{66}$ whereas black tea showed the greatest stimulation of bone mineralization. ${ }^{67}$

On the other hand, it has been observed that polyphenols in green tea increase bone formation and reduce bone resorption, ${ }^{25,66}$ especially tannic acid. ${ }^{66}$ Animals supplemented with green tea polyphenols and hydroxylated vitamin D3 mitigated bone loss in inflammation-induced or rheumatoid arthritis caused by osteoporosis. ${ }^{25}$ Another study in rats shows that a daily intake of $3.4 \mathrm{mg}$ EGCG $\mathrm{kg}^{-1}$ day $^{-1}$ for 3 months can help mitigate bone loss and also improve bone microarchitecture. ${ }^{25}$ EGCG can also improve the osteogenic differentiation of mesenchymal stem cells in the bone marrow. ${ }^{68}$ Overall, this study demonstrated for the first time that local treatment of EGCG can accelerate the fracture healing process, at least in part, via bone morphogenetic protein-2 (BMP-2). ${ }^{68}$ Green tea constituents such as catechins, theaflavins, kaempferol and phenolic acids have been seen to have estrogenic effects, which can influence bone health. ${ }^{69}$

Finally, lead $(\mathrm{Pb})$ and cadmium (Cd) are environmentally toxic metals. ${ }^{66}$ Regular consumption of white, black or green tea has been described to have a protective effect on bone metabolism and increased bone resorption during prolonged exposure to $\mathrm{Pb}$ and $\mathrm{Cd}$ in rats. ${ }^{25,66}$ While more studies are needed to confirm the in vivo effects, the results suggest that tea consumption can benefit bone health. ${ }^{67}$

\subsection{Antibacterial, antiviral, fungicide and antiparasitic activities}

There are many studies claiming that tea and some of its bioactive compounds, such as EGCG and EGC, are mainly responsible for antimicrobial activity, ${ }^{23,25,70}$ antiviral activity, $^{23,25,45,71-75}$ and fungicide $e^{23,45,70}$ and antiparasitic activity. ${ }^{70}$ These properties of tea became relevant thanks to the British Army Medical Corps that viewed black tea as helping to prevent various infections. ${ }^{76}$

Tea catechins showed the greatest anti-bacterial activity. One of their mechanisms is related to their binding capacity to cell membranes. Such binding allows catechins to alter the membrane and increase permeability, inducing cell lysis. ${ }^{70}$ In several studies, polyphenols from green tea extracts, particularly EGCG and ECG, were effective against Pseudomonas aeruginosa, Clostridium botulinum, Bacillus cereus, Escherichia coli, Salmonella and Staphylococcus aureus. ${ }^{23,25,70,77}$ They damaged the cell membrane affecting the regulation of peptidoglycan biosynthesis and generating an alteration in the structure of the cell wall. ${ }^{70}$ Lower concentrations of EGCG and ECG are necessary to exert effects on Gram-positive bacteria than on Gram-negative. ${ }^{23,25}$ Tea catechins and polyphenols (such as caffeic and gallic acids) also suppress the growth of Helicobacter pylori. ${ }^{23,25}$ An additional study revealed that green tea catechins could also be used to treat urinary tract infections. $^{23,25}$

Different studies have found that tea, and particularly EGCG, has antiviral effects against several viruses. The antiviral effects are associated with the inactivation of the virus by preventing adhesion, spread and replication. ${ }^{25}$ One of the described mechanisms is to inhibit the enzyme transcriptase that allows the virus to live within host cells. ${ }^{45}$ According to the review carried out by Sanlier et al., white tea had a greater antiviral effect. ${ }^{46}$ EGCG may be a potential alternative agent for viral diseases as it showed broad-spectrum antiviral activities in many viruses, including hepatitis $\mathrm{C}$ virus, hepatitis $\mathrm{B}$ virus, influenza, Herpes simplex virus, murine cytomegalovirus, reovirus and adenovirus, acting even against diseases related to the human papilloma virus..$^{23,25,71-74}$ In some cases, EGCG could effectively prevent and improve the symptoms of some viruses. $^{72,73}$ In epidemiological and experimental studies in humans the evidence was variable. 
Green tea consumption could reduce the incidence of influenza. ${ }^{74}$ Adsorption of green tea catechins into the pharyngeal mucosa through ingestion or gargle could serve to prevent infection. ${ }^{74}$ In addition, green tea can inhibit the infection of Dengue or Zika viruses in vitro. ${ }^{71,75}$

Regarding fungal infections, their treatment usually requires long-term therapy. ${ }^{23}$ Green tea extracts, especially catechins, have antifungal action, ${ }^{23,70}$ especially anti-candida in a $\mathrm{pH}$-dependent manner. ${ }^{23}$ Black tea was found to be the one with the highest anti-fungal activity. ${ }^{45}$ Finally, tea can be also used against parasitic infections by decreasing the number and growth of parasites. ${ }^{70}$

The effect of tea against SARS CoV-2 is a very promising area and will become an important trend in the future, but more studies will be needed. One example is the study by Gosh et al. where they provide three green tea polyphenols (EGCG, ECG and GCG) that may serve as potential inhibitors against SARS CoV-2 Mpro. ${ }^{72}$ This is a fundamental enzyme in the mediation of viral replication and transcription, and in this way it can act against coronavirus disease 2019 (COVID-19). ${ }^{71}$

\subsection{Effects on oral health}

Halitosis is a common condition in the mouth produced by some volatile compounds generated by different bacteria. It was seen how EGCG can regulate the microbial environment by inhibiting bacterial growth and the production of volatile compounds. $^{76}$ Dental cavities are also one of the most frequent problems related to oral health. Studies on cariogenic factors have shown that some types of teas and their components can be effective on bacterial activity and caries incidence. ${ }^{25,78-80}$ For example, extracts of black and white tea based on water and ethanol have significant activity against cariogenic pathogens. ${ }^{81}$

Green tea also showed a high effectiveness against cariogenic pathogens. The explanation behind is the influence of green tea in $\mathrm{pH}$ control. $^{78}$ In addition, according to Ghorbanoghli et al. green tea could also influence mouth health and help control periodontitis via antioxidants. ${ }^{79}$ On the other hand, in a study conducted by Nanri et al. with 7514 Japanese participants over the age of 65, it was found that a consumption of $\geq 3$ cups per day of green tea can increase oral health. ${ }^{82}$ Tea polyphenols, particularly EGCG, can reduce the growth and adhesion of oral bacteria to the glycoprotein layer on the tooth surface..$^{25,76,78,79}$ Moreover, Vilela et al. demonstrated that a mouthwash with green tea or an EGCG extract has antimicrobial activity (particularly the EGCG extract) in children, which further reduced bacterial levels in the oral cavity. ${ }^{83}$ This finding along with other studies supports the use of green tea and green tea extracts with a high EGCG content as a good alternative to chlorhexidine-based mouthwashes, ${ }^{78,79,82}$ especially for its effects in reducing bacterial density in prolonged uses (1-2 weeks). ${ }^{78}$ Its effects are promising, even longer term uses, but more studies are needed to see whether or not the effects will be significant. $^{79,80}$

\subsection{Effects on dermatological health and antiallergic effect}

Several studies have described the beneficial properties of green tea extracts on dermatological health. ${ }^{25,77,83}$ Green tea is effective in treating acne due to its anti-inflammatory and antioxidant properties. ${ }^{83}$ In a recent meta-analysis, the topical application of green tea extract significantly reduced the number of inflammatory lesions, while oral intake showed a slight effect thanks to its anti-inflammatory and antimicrobial properties. ${ }^{83}$ Furthermore, green tea extracts have been related to wound healing. According to the results shown by Kalalinia et al., the topical formulation of green tea extract shows great potential for anti-haemorrhage applications. It was found that tea tannins can affect haemostasis, reducing bleeding time and promoting the wound healing process by significantly reducing bleeding time. ${ }^{78}$

Polyphenols exert some protection against harmful effects of UV rays on collagen. ${ }^{25}$ Topical application of green tea polyphenols can reduce skin flaking. ${ }^{25}$ Catechins control the activity of collagenase and elastase and help maintain skin elasticity, and in particular a positive effect of EGCG has been observed on psoriasis. ${ }^{25}$ In general, the main results are related to the topical use, but more studies would be interesting to check such effects after oral administration. ${ }^{25}$

Green tea could serve as an alternative for the treatment of allergic rhinitis. The latest research reported that the consecutive consumption of $700 \mathrm{ml}$ of high EGCG green tea for one month could alleviate symptoms such as runny nose, itching eyes and watering eyes in people with Japanese cedar pollinosis. ${ }^{84}$ In a mouse model with allergic rhinitis, oral administration of EGCG decreased the occurrence of nasal rubbing and the number of sneezes. The level of immunoglobulin E, histamine and proinflammatory cytokines was also lower in the EGCG-treated mice. ${ }^{84}$

\subsection{Effects on stress and brain function}

Many investigations claim healthy effects of tea and its bioactive compounds on mental health, ${ }^{85}$ memory and learning, ${ }^{29,86}$ stress, ${ }^{17,23,25,87}$ anxiety, ${ }^{17,23,25,85,87}$ depression, ${ }^{85,88}$ and neurodegenerative diseases. ${ }^{29,86,89-94}$

Depression is one of the most common psychiatric disorders, whereas stress is a major risk factor for depression. Tea consumption reduces the risk of depression. ${ }^{88}$ Caffeine can be one of the therapeutic agents for motivational dysfunction in depression. ${ }^{88}$ Jalalmanesh et al. performed a clinical trial with 150 Iranian nurses, studying the effect of green tea on mental health after drinking 3 glasses of green tea for 6 weeks. The results showed that the consumption of green tea improved mental health and the dimensions of physical health and reduced anxiety disorder, sleep disorder and depression risk. ${ }^{86}$ Furthermore, in a longitudinal study in a Japanese population carried out by Shirai et al., the intake of green tea and coffee was evaluated in relation with cognitive decline. This study included more than 2000 people between 40 and 79 years old and was carried out for 10 years. It was found that green tea intake reduces the risk of cognitive impairment by $28 \%$ in 
older adults. However, certain factors are not clear for the primary prevention of dementia and cognitive impairment, so that more studies are needed to support these results. ${ }^{87}$

Theanine is one of the most abundant amino acids in tea and has a similar structure to the excitatory neurotransmitter glutamic acid (Glu) and the inhibitory neurotransmitter gamma-aminobutyric acid (GABA).$^{90}$ This means that theanine has neuroprotective $\mathrm{in}^{17,23,25,90}$ and antistress effects under resting conditions. ${ }^{17,23,25,87}$ It is considered an anxiolytic agent because people who consumed green tea felt relaxed and calm. ${ }^{17,23,25,87}$ In human studies, theanine intake created relaxation in 30-40 min by two different mechanisms: firstly, theanine consumption directly activates the production of $\alpha$ waves in the brain, creating a condition of relaxation; secondly, tea consumption modulates inhibitors such as GABA that affect other key neurotransmitters of relaxation. ${ }^{25}$ It is estimated that the effective theanine intake could be around 200 to $400 \mathrm{mg}$ day $^{-1} \cdot{ }^{87}$ It has also been shown that theanine consumption in animals has an impact on learning ability although more human trials are needed. ${ }^{17}$

Green tea catechins play also a role in memory and cognitive performance. ${ }^{29}$ Consumption of green tea for more than 5 years was associated with a significantly lower rate of dementia. Green tea extract improved working memory processing. ${ }^{29}$ A single dose of $300 \mathrm{mg}$ of EGCG in healthy volunteers significantly improved brain activity, by increasing the $\alpha, \beta$ and $\theta$ waves in the frontal and central parts of the midline of the brain. The therapeutic effect of EGCG-enriched green tea extract on neurodegeneration was reported. ${ }^{29}$ EGCG had some of the neuroprotective effects against neural injury and Huntington's disease, amyotrophic lateral sclerosis and more prevalent neurodegenerative diseases. ${ }^{89}$ Catechins in green tea extract have neuroprotective and memory-enhancing effects in an animal model of Parkinson's disease. They also suppressed the formation of amyloid plaques and halted immunohistochemical alteration and oxidative damage. ${ }^{29}$ Gallic acid and pyrogallol also showed an effect, but the potency was lower than that of EGCG. ${ }^{29}$

Alzheimer's disease is characterized by the aggregation of the amyloid-beta protein $(A \beta)$, which is neurotoxic, and the attenuation of neurotransmission, resulting in neurodegeneration. An in vitro study carried out by Li demonstrated that several tea bioactive compounds (such as EGCG and ECG) were able to protect neuronal cells by inhibiting the aggregation of $\mathrm{A} \beta$. The main neuroprotective effect was exerted by white tea. ${ }^{94}$ This effect corroborates the results seen in green tea extracts processed at high temperature, which effectively inhibit the generation of ROS and the formation of $\mathrm{A} \beta$ fibrils in the brain tissue, ${ }^{93}$ with the EGCG being the most effective component. $^{29}$

Acetylcholinesterase and butyrylcholinesterase are therapeutic targets in Alzheimer's disease. EGCG was the only compound found to produce a significant competitive inhibition of acetylcholinesterase and therefore could restore synaptic concentrations of acetylcholine. ${ }^{92}$ The mechanisms supporting these results are antioxidant activity and reduction of brain inflammation. Brain inflammation is considered to play an important role in dementia. EGCG exhibits neuroprotective effects as it improves endothelial function. ${ }^{91}$ Not all research reflects these effects, and according to Kakutani et al., green tea intake was not significantly associated with improved memory impairment and was opposite to that of a German cohort. They attribute these results to ethnic and genetic background resulting in different metabolic responses. ${ }^{92}$

\subsection{Lung health effects}

Acute lung injury and acute respiratory distress syndrome are serious clinical complications with high morbidity and mortality. ${ }^{95}$ A study in mice showed that treatment with EGCG improved histopathological lesions, reduced pro-inflammatory markers and improved lung regeneration capacity by improving the expression of Ki67, PCNA and Ang-1 proteins. ${ }^{95}$

\subsection{Effects on fertility}

Combinations of green tea with different herbs are currently being used as new therapies to improve the fertility rate and treat infertility in humans and animals. However, they can exert an opposite effect at high concentrations. ${ }^{96}$ EGCG can stimulate and regulate the hormones that govern the menstrual cycle. They can also modulate the levels of progesterone and oestrogenic hormones, as well as improve fertility, and are a possible treatment for increasing the pregnancy rate. ${ }^{96}$ Testicular tissue is predisposed to the action of free radicals due to its high rate of cell division. Thanks to the antioxidant properties of green tea, inflammation and DNA fragmentation can be reduced, and sperm motility and viability can be increased. ${ }^{96}$

\subsection{Effect on the liver system}

Bile acids are powerful regulators of metabolism. Sun et al. carried out a trial in which they administered different types of teas to female rats for 28 days. Metabolomic analyses showed variations in the levels and metabolism of various bile acids. This change in bile acid metabolism may be associated with the beneficial health effects of tea. ${ }^{98}$ This confirms other research where green tea extracts reversed liver damage by reducing oxidative damage induced by contaminants in rats. ${ }^{25}$ In other animal studies, green tea extracts (particularly rich in EGCG) can effectively mitigate non-alcoholic fatty liver disease. ${ }^{98}$ Furthermore, green tea reduced the activity of the nuclear factor-kappa $\beta$, which is involved in the development of liver inflammation. ${ }^{99}$ Even white tea showed excellent potential in preventing liver damage due to its antioxidant effects. $^{25,100}$ According to Sanlier et al., both EGCG and white tea extract limited the oxidative damage of hepatocytes and red blood cells caused by Benzo (a) pyrene. ${ }^{46}$

In humans, green tea consumption and EGCG supplementation reduced liver enzyme levels and modulated bilirubin. This effect was observed in subjects with hepatic damage, whereas for healthy individuals a detrimental effect was observed. ${ }^{99}$ Given the variability of the results and the possible toxic effects, further studies are necessary. 


\section{Adverse and toxic effects of tea and its bioactive compounds}

Regardless of the many health benefits described for tea consumption, there is evidence that some adverse effects may occur. Toxic effects for some tea products have been described, though mainly at high concentrations or during certain physiological periods. $^{22,23,26,29,37,102-112}$ Several safety and toxicological evaluations of tea and its bioactive compounds have been carried out in vitro, in animal models and on humans. ${ }^{102}$ Toxicity normally depends on several factors, such as the concentration of the toxin or the type and duration of exposure. ${ }^{103}$ Except in Asian countries, where tea consume can exceed even 5 cups per day, the rest of the countries have low tea and tea extract intakes. ${ }^{102,105}$

Liver toxicity is one of the most important complications in most studies, reviews and meta-analyses. ${ }^{23,26,29,102-104}$ Catechins, particularly high concentrations of EGCG, have the highest hepatotoxicity effect. ${ }^{29,104}$ Acute dose-dependent toxicity has been described. ${ }^{103,104}$ The pro-oxidant properties of these compounds (due to high concentrations) are the main mechanism of hepatic cytotoxicity. ${ }^{26,103}$ At high concentrations, EGCG is able to modulate the potential of the mitochondrial membrane and induce the formation of reactive oxygen species, ${ }^{103}$ which produce oxidative damage capable of degrading cellular DNA. ${ }^{23}$ Damage caused by increased lipid peroxidation has also been described. ${ }^{104}$

According to the European Food Safety Authority, the average daily intake of EGCG from the consumption of green tea infusions ranges from 90 to $300 \mathrm{mg}$ day $^{-1}$, with up to $866 \mathrm{mg}$ day $^{-1}$ in heavy tea drinkers. ${ }^{105}$ Liver toxicity cannot be established for regular consumption of traditional tea infusions, since the incidence of adverse effects is rare and is only detected in some consumers, although these data should be taken into account. ${ }^{102,104,105}$

Green tea consumption has been shown to produce also nutrient-nutrient interactions. ${ }^{37}$ All studies indicate a decrease in iron ${ }^{23,37,103}$ and folic acid bioavailability. ${ }^{103}$ A cross-sectional study in Pakistan with about 400 pregnant women investigated maternal tea consumption during pregnancy, and the risk of developing iron deficiency anaemia. Serum iron and ferritin were significantly higher in non-tea drinkers, while total iron-binding capacity increased significantly in tea drinkers. Anaemia was found in pregnant women who drank tea. Lower tea consumption was suggested during pregnancy and never near mealtime. ${ }^{107}$ Additionally, during pregnancy there was also a decrease in the serum folate level. ${ }^{103}$ This effect is due to various mechanisms, such as the presence of caffeine and other methylxanthines, ${ }^{23}$ capable of complexing nutrients or irritating the gastrointestinal lining. ${ }^{103,104}$

Sub-acute toxicity has been described, presenting localised gastric effects. ${ }^{103}$ Gastrointestinal damage depends on the dose, and can range from mild gastric erosion to occasional diarrhoea and vomits ${ }^{22,37,104}$ to dilation, ulceration, even severe effects. ${ }^{104}$ Adverse effects were shown to be reduced if the intake occurred after the meal. ${ }^{104}$
The consumption of tea extracts also affects the level of absorption, bioavailability, activity and elimination of drugs. ${ }^{103,106}$ Tea can induce hydrophilic effects and conjugation reactions. Different reviews highlight interactions with amoxicillin, ${ }^{103,106}$ codeine, atropine, ephedrine or warfarin. ${ }^{103}$

Ocular and skin toxicity were observed after topical administration of EGCG. ${ }^{103}$ In rats, sensitivity of the nasal cavity was also found. ${ }^{103}$ A study in Assam (India) by Kumar et al. found a higher incidence (48\%) of placental weight loss and low birth weight. This was attributed to different factors such as intensity of work, health and socio-economic levels, increased exposure to pesticides and heavy metals. ${ }^{108}$ However, another possibility could be related to the chronic toxic effect of prolonged exposure to tea. Further studies in this matter would be necessary.

High doses of green tea can generate other side effects such as headaches, insomnia or tachycardia. ${ }^{22,37}$ These toxicological findings can be derived from liver and gastrointestinal toxicity. ${ }^{104}$ No toxic effects on the viability of normal cells were demonstrated if the viability of the cancer cells was decreased, thus demonstrating selective toxicity. ${ }^{103}$ There is no enough evidence on thyroid toxicity. ${ }^{104}$ Theanine consumption has not demonstrated any adverse effect on humans. ${ }^{23}$ The same results have been found for catechin intake. ${ }^{103}$ However, high intakes of tea can cause some sleep disorders in babies during breastfeeding. ${ }^{103}$

Tea consumption during pregnancy may be associated with an increased risk of premature birth and with different parameters related to foetal growth, although there is not enough conclusive evidence. Current studies suggest that maternal intake of polyphenols, especially during the third trimester of pregnancy, could be associated with foetal ductal constriction and, therefore, involve an increased risk of low birth weight or more severe complications. ${ }^{109,111}$ Anti-inflammatory and antioxidant effects suggest to be counterproductive in the third trimester of pregnancy. ${ }^{109}$ The suspension of flavonoid-rich drinks produced a reversal of foetal ductal constriction. ${ }^{109}$ Even the Brazilian foetal cardiology guide presented recommendations to restrict the consumption of products rich in polyphenols, such as tea, during the last trimester of pregnancy. ${ }^{111}$

A study by Lu et al. on occasional tea consumption during pregnancy did not find associations with an increased risk of premature birth or abnormal foetal growth. ${ }^{110}$ Given the high number of births in China and its high tea consumption, the findings may suggest an ethnic effect. ${ }^{110}$ Caffeine intake during pregnancy can also affect the new-born weight, length or head circumference. ${ }^{112}$ The limit for consumption is $200 \mathrm{mg}$ day $^{-1}$ of caffeine, but there are still studies that differ in terms of its toxicity during pregnancy. ${ }^{112}$ Wierzejska et al. evaluated the caffeine intake of 100 Polish pregnant women. Only $2 \%$ of the women exceeded the caffeine intake limits, $60 \%$ coming from black tea. ${ }^{112}$

In summary, the main side effects of tea consumption and its components in acute, sub-acute and chronic tests are mild but diverse. The most frequent effects are hepatotoxicity, inter- 
action with drugs and nutrients such as iron, gastrointestinal alterations (such as vomiting and diarrhoea) and effects on the health of babies. The reviews and meta-analyses show a great heterogeneity in the results. ${ }^{104}$ Although the effects are minimal and rare in general, the evidence shows that green tea infusions are safe in a wide range of intakes and conditions. ${ }^{104,105}$ However, limiting intake is recommended in kidney and liver disease and during pregnancy or lactation to limit likely side effects in susceptible individuals. $^{103}$

\section{New approaches and developments}

Currently, approaches based on omics sciences provide more information on the potential of bioactive compounds, their association, interactions and their possible genetic role. ${ }^{113}$ In this sense, omics sciences are showing a plethora of information related to the interaction of tea with the gut microbiota. There is strong evidence that the gut microbiota provides information about different characteristics, such as geographical location, nutrition or host genetics. ${ }^{114}$ The gut microbiota is composed of a large number of bacterial species and modulates the gastrointestinal system. ${ }^{114}$ Gut microbiota can regulate the immune system, prevent chronic diseases and affect the metabolism and bioavailability of different compounds. ${ }^{84,113,114}$ Meta-analytical methods showed that the consumption of tea, specifically black tea, ${ }^{114}$ oolong tea ${ }^{115}$ and green tea ${ }^{116}$ affected the abundance of gut microbiota in a dose-dependent manner. ${ }^{116}$

Green tea polyphenols can modulate the diversity and composition of the gut microbiota. ${ }^{84,86,97,113-123}$ Studies suggest that they promote the growth of specific bacteria, mainly beneficial bacterial species such as Bifidobacterium spp., Lactobacillus spp., Clostridium coccoides, Actinobacteria and Firmicutes, while inhibiting the proliferation of pathogenic bacterial species such as Clostridium perfringens, Clostridium difficile, Bacteroides spp., E. coli $\mathrm{O} 157$ and Helicobacter pylori. ${ }^{84,114,115,117,124}$ These changes in turn affect the host health. The antibacterial activity can be explained by the binding of polyphenols to bacterial membrane proteins, and their pro-oxidant effect (which will alter the permeability) and the possible inhibition of glucose transport ${ }^{84,117}$ and changes in the metabolic profile of bile acids. ${ }^{97}$ In contrast, the increase in beneficial bacteria could be related to the prebiotic effects of tea phenolic compounds. ${ }^{115,117,118,122,123}$

Absorption in the intestinal tract depends on bioavailability. Green tea phenolic compounds, in particular catechins, have a low bioavailability. ${ }^{84}$ Those phenolic compounds that are not absorbed are metabolized in the colon by microbial enzymes, leading to the formation of metabolites (such as acetic, propionic and succinic acids) with major metabolic implications. ${ }^{84,113,117,118}$ These compounds are able to regulate the functions of the intestinal barrier and directly affect physiological changes. An example is the hydrolysis of
EGCG, which releases gallic acid, which has a high rate of metabolization by the gut microbiota. ${ }^{84}$ EGCG has the greatest affinity for interacting with mucins, being able to generate a selective barrier and helping in the defence against pathogens. ${ }^{120}$ In addition, EGCG modulates different cytokines and acts against intestinal inflammation. ${ }^{119,121}$

In Japan, green tea has been traditionally consumed and its polyphenols are likely to be metabolized by intestinal bacteria and/or specific enzymes among the Japanese population. ${ }^{86}$ This confirms the possibility of an ethnic factor in the bioavailability and metabolism of tea polyphenols. These factors may increase the possible beneficial or toxic effects. More omics studies are necessary as this new approach can provide answers and open new strategies for the treatment of diseases. ${ }^{84,97,117}$

Farag et al. evaluated the impact of tea on different metabolic pathways in a gut microbiota model. In particular, these authors studied the effect of black and green tea extracts in the eight bacterial species more abundant in the human gut microbiota. A decrease in sugars and amino acids was observed, as well as an increase in gallic acid and purine levels. A high concentration of methylxanthines and GABA was also found, which worked as a direct substrate in the metabolism of the microbiota. ${ }^{113}$

Fluctuations in circadian rhythm also affect the gut microbiota. Gut microorganisms can regulate brain activity by means of GABA production. ${ }^{122}$ GABA plays a crucial role in modulating neuronal signals and circadian rhythms. ${ }^{122,123}$ Customized approaches to consume phenolic compounds at specific times can maximize their specific prebiotic effects to remodel intestinal microbiota and circadian rhythm disorders. $^{122,123}$

Currently, many products are trying to take advantage of the properties of tea and its biological compounds. ${ }^{9,10,23,125}$ There is growing interest among consumers for green tea supplements. In recent years, there has been a shift from consuming tea beverages to the intake of tea in solid form. In this sense, several products based on tea have been developed, such as green tea cake, green tea noodles, green tea bread or tea ice cream. ${ }^{10}$ These foods are also considered functional foods. ${ }^{23}$ The addition of different tea extracts to white chocolates positively influenced antioxidant activity by more than doubling the total amount of polyphenols, flavonoids and phenolic acids. The best results were obtained with the addition of green teas. ${ }^{125}$ The use of green tea extracts in the manufacture of yoghurt, wheat dough or biscuits has also shown encouraging results. ${ }^{126}$

At present, some compounds such as theanine or polyphenols, (specifically green tea catechins) are being used as a food additive with technological functions, ${ }^{23}$ being antioxidants and anti-bacterial are their main effects. ${ }^{126,127}$ In the study conducted by Lorenzo et al. green tea extracts in meat products inhibited the development of undesirable microorganisms and improved shelf life. ${ }^{126}$ The incorporation of green tea polyphenols effectively inhibited bacterial growth and lipid oxidation in lamb sausages. It did not improve the sensory 
quality although it reduced odour by inhibiting specific lipids. ${ }^{127}$ Overall, studies revealed that green tea extracts improved meat quality characteristics such as meat colour and shelf life and reduced lipid oxidation. ${ }^{126,127}$ On the other hand, high pressure processing has a higher extraction yield of bioactive ingredients. This means that cold processed white tea could be a viable alternative to hot tea, as the bioactive compounds were retained to a greater extent. ${ }^{9}$

Green tea is also used in cosmetic products ${ }^{10}$ or in animal feed. ${ }^{128}$ Supplementing the diet of laying hens with green tea extract improves egg production, the quality and free amino acid, fatty acid and antioxidant profiles of eggs. ${ }^{128}$ Due to its excellent biocompatibility, antioxidant activity and anticarcinogenic capacity, tea EGCG is being used in health materials, such as multifunctional nanomaterials, targeted nanoparticles and self-assembled nanogels. ${ }^{76}$

\section{Conclusions}

Tea is one the most consumed beverages around the world, which probably makes it also one of the most studied. Tea is potentially beneficial for a number of health conditions related to oxidative stress, inflammation, obesity and cancer, among others. Most tea benefits have been associated with different bioactive compounds, mostly phenolic compounds, and specifically catechins. The antioxidant capacity of these compounds after entering the systemic circulation is responsible for most of their beneficial effects. However, the most promising results come from in vitro studies or in experimental animal models. Under certain conditions, it is possible that tea, even if weak, could present some specific toxicity or alteration effects on the intestinal absorption of some nutrients. On the other hand, the findings on the modulation of the gut microbiota and the new trends on its use as a feed, additive or in materials are remarkable. Therefore, even though there are good prospects, there is still much work to do since large human trials are needed to confirm tea benefits.

\section{Author contributions}

Conceptualization, S. P. C. and J. A. R. H.; methodology, S. P. B. and D. H. N.; writing-original draft preparation, D. H. N. writing-review and editing, S. P. B., S. P. C. and J. A. R. H.; funding acquisition, J. A. R. H. All authors have read and agreed to the published version of the manuscript.

\section{Conflicts of interest}

The authors declare that there is no conflict of interest regarding the publication of this paper.

\section{Acknowledgements}

This work is part of the doctoral thesis of Daniel HinojosaNogueira conducted within the context of the "Program of Nutrition and Food Sciences" at the University of Granada. This work was supported by the "Plan propio de Investigación y Transferencia" of the University of Granada under the program "Intensificación de la Investigación, modalidad B" granted to José A. Rufián-Henares.

\section{References}

1 W.-H. Cheng, Green Tea: An Ancient Antioxidant Drink for Optimal Health?, J. Nutr., 2019, 149, 18771879.

2 H. Vishnoi, R. B. Bodla and R. Kant, Green tea (camellia sinensis) and its antioxidant property: a review, Int. J. Pharma Sci. Res., 2018, 9(5), 1723-1736.

3 U. Röschenthaler, Chinese Green Tea in Mali, Cultural Mobility and African Agency in the Global South, Afr. Asian Stud., 2020, 19, 133-156.

4 F. Hajiaghaalipour, J. Sanusi and M. S. Kanthimathi, Temperature and Time of Steeping Affect the Antioxidant Properties of White, Green, and Black Tea Infusions: Tea infusion and antioxidant properties, J. Food Sci., 2016, 81, H246-H254.

5 C.-N. Zhao, G.-Y. Tang, S.-Y. Cao, X.-Y. Xu, R.-Y. Gan, Q. Liu, Q.-Q. Mao, A. Shang and H.-B. Li, Phenolic Profiles and Antioxidant Activities of 30 Tea Infusions from Green, Black, Oolong, White, Yellow and Dark Teas, Antioxidants, 2019, 8, 215.

6 S. Pérez-Burillo, R. Giménez, J. A. Rufián-Henares and S. Pastoriza, Effect of brewing time and temperature on antioxidant capacity and phenols of white tea: Relationship with sensory properties, Food Chem., 2018, 248, 111-118.

7 Q. Chen, J. Shi, B. Mu, Z. Chen, W. Dai and Z. Lin, Metabolomics combined with proteomics provides a novel interpretation of the changes in nonvolatile compounds during white tea processing, Food Chem., 2020, 332, 127412.

8 S. Pastoriza, M. Mesías, C. Cabrera and J. A. RufiánHenares, Healthy properties of green and white teas: an update, Food Funct., 2017, 8, 2650-2662.

9 S. Uzuner and G. A. Evrendilek, Functional responses of cold brewed white tea to high pressure processing, J. Food Process Eng., 2019, 42(5), e13098.

10 P. Peng, L. Wang, G. Shu, J. Li and L. Chen, Nutrition and aroma challenges of green tea product as affected by emerging superfine grinding and traditional extraction, Food Sci. Nutr., 2020, 8, 4565-4572.

11 C. Li, B. Zong, H. Guo, Z. Luo, P. He, S. Gong and F. Fan, Discrimination of white teas produced from fresh leaves with different maturity by near-infrared spectroscopy, Spectrochim. Acta, Part A, 2020, 227, 117697. 
12 Y. Wang, Z. Kan, H. J. Thompson, T. Ling, C.-T. Ho, D. Li and X. Wan, Impact of Six Typical Processing Methods on the Chemical Composition of Tea Leaves Using a Single Camellia sinensis Cultivar, Longjing 43, J. Agric. Food Chem., 2019, 67, 5423-5436.

13 Z.-T. Fang, C.-J. Song, H.-R. Xu and J.-H. Ye, Dynamic changes in flavonol glycosides during production of green, yellow, white, oolong and black teas from Camellia sinensis L. (cv. Fudingdabaicha), Int. J. Food Sci. Technol., 2019, 54, 490-498.

14 J. Zhang, X. Wei, W. Dai and Z. Lin, Study of enrichment difference of 64 elements among white tea subtypes and tea leaves of different maturity using inductively coupled plasma mass spectrometry, Food Res. Int., 2019, 126, 108655.

15 B. Wen, S. Ren, Y. Zhang, Y. Duan, J. Shen, X. Zhu, Y. Wang, Y. Ma, Z. Zou and W. Fang, Effects of geographic locations and topographical factors on secondary metabolites distribution in green tea at a regional scale, Food Control, 2020, 110, 106979.

16 L. Chen, H. Mo, L. Zhao, W. Gao, S. Wang, M. M. Cromie, C. Lu, J.-S. Wang and C.-L. Shen, Therapeutic properties of green tea against environmental insults, J. Nutr. Biochem., 2017, 40, 1-13.

17 J. Williams, D. Sergi, A. J. McKune, E. N. Georgousopoulou, D. D. Mellor and N. Naumovski, The beneficial health effects of green tea amino acid 1 -theanine in animal models: Promises and prospects for human trials: L-theanine in animal models; promises and prospects for human trials, Phytother. Res., 2019, 33, 571-583.

18 M. Monobe, Health Functions of Compounds Extracted in Cold-water Brewed Green Tea from Camellia Sinensis L., Jpn. Agric. Res. Q. JARQ, 2018, 52, 1-6.

19 J. Pan, Y. Jiang, Y. Lv, M. Li, S. Zhang, J. Liu, Y. Zhu and H. Zhang, Comparison of the main compounds in Fuding white tea infusions from various tea types, Food Sci. Biotechnol., 2018, 27, 1311-1318.

20 S. Pastoriza, S. Pérez-Burillo and J. Á. Rufián-Henares, How brewing parameters affect the healthy profile of tea, Curr. Opin. Food Sci., 2017, 14, 7-12.

21 S. Pérez-Burillo, A. Jiménez-Zamora, J. Párraga, J. A. Rufián-Henares and S. Pastoriza, Furosine and 5-hydroxymethylfurfural as chemical markers of tea processing and storage, Food Control, 2019, 99, 73-78.

22 A. Jiménez-Zamora, C. Delgado-Andrade and J. A. RufiánHenares, Antioxidant capacity, total phenols and color profile during the storage of selected plants used for infusion, Food Chem., 2016, 199, 339-346.

23 T. C. Dinh, T. N. Thi Phuong, L. B. Minh, V. T. Minh Thuc, N. D. Bac, N. Van Tien, V. H. Pham, P. L. Show, Y. Tao, V. T. Nhu Ngoc, N. T. Bich Ngoc, A. Jurgoński, D. B. Thimiri Govinda Raj, P. Van Tu, V. N. Ha, J. Czarzasta and D.-T. Chu, The effects of green tea on lipid metabolism and its potential applications for obesity and related metabolic disorders - An existing update, Diabetes Metab. Syndr. Clin. Res. Rev., 2019, 13, 1667-1673.
24 M. Saeed, M. Naveed, M. Arif, M. U. Kakar, R. Manzoor, M. E. Abd El-Hack, M. Alagawany, R. Tiwari, R. Khandia, A. Munjal, K. Karthik, K. Dhama, H. M. N. Iqbal, M. Dadar and C. Sun, Green tea (Camellia sinensis) and 1 -theanine: Medicinal values and beneficial applications in humans-A comprehensive review, Biomed. Pharmacother., 2017, 95, 1260-1275.

25 Z. Yan, Y. Zhong, Y. Duan, Q. Chen and F. Li, Antioxidant mechanism of tea polyphenols and its impact on health benefits, Anim. Nutr., 2020, 6, 115-123.

26 M. Saeed, M. E. Abd El-Hac, M. Alagawany, M. Naveed, M. A. Arain, M. Arif, R. N. Soomro, M. Kakar, R. Manzoor, R. Tiwari, R. Khandia, A. Munjal, K. Karthik, K. Dhama, H. M. N. Iqbal and C. Sun, Phytochemistry, Modes of Action and Beneficial Health Applications of Green Tea (Camellia sinensis) in Humans and Animals, Int. J. Pharmacol., 2017, 13, 698-708.

27 O. Asbaghi, F. Fouladvand, M. J. Gonzalez, V. Aghamohammadi, R. Choghakhori and A. Abbasnezhad, The effect of green tea on C-reactive protein and biomarkers of oxidative stress in patients with type 2 diabetes mellitus: A systematic review and metaanalysis, Complement. Ther. Med., 2019, 46, 210-216.

28 F. Haghighatdoost and M. Hariri, The effect of green tea on inflammatory mediators: A systematic review and meta-analysis of randomized clinical trials, Phytother. Res., 2019, 33, 2274-2287.

29 S. U. Rahman, Y. Li, Y. Huang, L. Zhu, S. Feng, J. Wu and $\mathrm{X}$. Wang, Treatment of inflammatory bowel disease via green tea polyphenols: possible application and protective approaches, Inflammopharmacology, 2018, 26, 319-330.

30 M. H. Farzaei, R. Bahramsoltani, Z. Abbasabadi, N. Braidy and S. M. Nabavi, Role of green tea catechins in prevention of age-related cognitive decline: Pharmacological targets and clinical perspective, J. Cell. Physiol., 2019, 234, 2447-2459.

31 J. K. Hodges, J. Zhu, Z. Yu, Y. Vodovotz, G. Brock, G. Y. Sasaki, P. Dey and R. S. Bruno, Intestinal-level antiinflammatory bioactivities of catechin-rich green tea: Rationale, design, and methods of a double-blind, randomized, placebo-controlled crossover trial in metabolic syndrome and healthy adults, Contemp. Clin. Trials Commun., 2020, 17, 100495.

32 S. K. Abe and M. Inoue, Green tea and cancer and cardiometabolic diseases: a review of the current epidemiological evidence, Eur. J. Clin. Nutr., 2020, 1-12.

33 W. Lee, D. Lee, E. Han and J. Choi, Intake of green tea products and obesity in nondiabetic overweight and obese females: A systematic review and meta-analysis, J. Funct. Foods, 2019, 58, 330-337.

34 K. Luo, C. Ma, S. Xing, Y. An, J. Feng, H. Dang, W. Huang, L. Qiao, J. Cheng and L. Xie, White tea and its active polyphenols lower cholesterol through reduction of very-lowdensity lipoprotein production and induction of LDLR expression, Biomed. Pharmacother., 2020, 127, 110146. 
35 A. Rocha, A. P. Bolin, C. A. L. Cardoso and R. Otton, Green tea extract activates AMPK and ameliorates white adipose tissue metabolic dysfunction induced by obesity, Eur. J. Nutr., 2016, 55, 2231-2244.

36 R. Xu, K. Yang, S. Li, M. Dai and G. Chen, Effect of green tea consumption on blood lipids: a systematic review and meta-analysis of randomized controlled trials, Nutr. J., 2020, 19, 48.

37 M. Kobayashi and I. Ikeda, Mechanisms of Inhibition of Cholesterol Absorption by Green Tea Catechins, Food Sci. Technol. Res., 2017, 23, 627-636.

38 Y. Lin, D. Shi, B. Su, J. Wei, M.-A. Găman, M. S. Macit, I. J. B. do Nascimento and N. S. Guimaraes, The effect of green tea supplementation on obesity: A systematic review and dose-response meta-analysis of randomized controlled trials, Phytother. Res., 2020, 34, 2459-2470.

39 Y. Yonekura, M. Terauchi, A. Hirose, T. Odai, K. Kato and N. Miyasaka, Daily Coffee and Green Tea Consumption Is Inversely Associated with Body Mass Index, Body Fat Percentage, and Cardio-Ankle Vascular Index in MiddleAged Japanese Women: A Cross-Sectional Study, Nutrients, 2020, 12, 1370.

40 H. T. A. Sultane and E. M. Cambaza, Update on the Evaluation of the Anti-Obesity Effect of Green Tea (Camellia sinensis), Clin. Exp. Health Sci., 2020, 10, 16-20.

41 R. Bagheri, A. Rashidlamir, D. Ashtary-Larky, A. Wong, M. Alipour, M. S. Motevalli, A. Chebbi, I. Laher and H. Zouhal, Does green tea extract enhance the antiinflammatory effects of exercise on fat loss?, Br. J. Clin. Pharmacol., 2020, 86, 753-762.

42 R. Bagheri, A. Rashidlamir, D. Ashtary-Larky, A. Wong, B. Grubbs, M. S. Motevalli, J. S. Baker, I. Laher and H. Zouhal, Effects of green tea extract supplementation and endurance training on irisin, pro-inflammatory cytokines, and adiponectin concentrations in overweight middle-aged men, Eur. J. Appl. Physiol., 2020, 120, 915923.

43 Y. Kishimoto, E. Saita, C. Taguchi, M. Aoyama, Y. Ikegami, R. Ohmori, K. Kondo and Y. Momiyama, Associations between Green Tea Consumption and Coffee Consumption and the Prevalence of Coronary Artery Disease, J. Nutr. Sci. Vitaminol., 2020, 66, 237-245.

44 R. Xu, K. Yang, J. Ding and G. Chen, Effect of green tea supplementation on blood pressure: A systematic review and meta-analysis of randomized controlled trials, Medicine, 2020, 99, e19047.

45 C. D. Fox, C. T. Garner, P. W. Mumford, D. T. Beck and M. D. Roberts, Higher doses of a green tea-based supplement increase post-exercise blood flow following an acute resistance exercise bout in recreationally resistance-trained college-aged men, J. Int. Soc. Sports Nutr., 2020, 17, 27.

46 N. Sanlier, İ. Atik and A. Atik, A minireview of effects of white tea consumption on diseases, Trends Food Sci. Technol., 2018, 82, 82-88.

47 T. Atia, H. I. Sakr, A. A. Damanhory, K. Moawad and M. Alsawy, The protective effect of green tea on diabetes- induced hepato-renal pathological changes: a histological and biochemical study, Arch. Physiol. Biochem., 2020, 112.

48 X. Xia, J. Xu, X. Wang, H. Wang, Z. Lin, K. Shao, L. Fang, C. Zhang and Y. Zhao, Jiaogulan tea (Gpostemma pentaphyllum) potentiates the antidiabetic effect of white tea via the AMPK and PI3K pathways in C57BL/6 mice, Food Funct., 2020, 11, 4339-4355.

49 J. Yu, P. Song, R. Perry, C. Penfold and A. R. Cooper, The Effectiveness of Green Tea or Green Tea Extract on Insulin Resistance and Glycemic Control in Type 2 Diabetes Mellitus: A Meta-Analysis, Diabetes Metab. J., 2017, 41, 251.

50 X. Liu, W. Xu, H. Cai, Y.-T. Gao, H. Li, B.-T. Ji, X. Shu, T. Wang, R. E. Gerszten, W. Zheng, Y.-B. Xiang and X.-O. Shu, Green tea consumption and risk of type 2 diabetes in Chinese adults: the Shanghai Women's Health Study and the Shanghai Men's Health Study, Int. J. Epidemiol, 2018, 47, 1887-1896.

51 R. Xu, Y. Bai, K. Yang and G. Chen, Effects of green tea consumption on glycemic control: a systematic review and meta-analysis of randomized controlled trials, Nutr. Metab., 2020, 17, 56.

52 S. I. Nasrul and A. Sehgal, Antilithogenic potential of green tea, oolong tea, and black tea, Pharmacogn. Res., 2020, 12, 92.

53 X. Shu, H. Cai, Y. Xiang, H. Li, L. Lipworth, N. L. Miller, W. Zheng, X. Shu and R. S. Hsi, Green tea intake and risk of incident kidney stones: Prospective cohort studies in middle-aged and elderly Chinese individuals, Int. J. Urol., 2019, 26, 241-246.

54 R. Kanlaya and V. Thongboonkerd, Protective Effects of Epigallocatechin-3-Gallate from Green Tea in Various Kidney Diseases, Adv. Nutr., 2019, 10, 112-121.

55 D. Hayashi, L. Wang, S. Ueda, M. Yamanoue, H. Ashida and Y. Shirai, The mechanisms of ameliorating effect of a green tea polyphenol on diabetic nephropathy based on diacylglycerol kinase $\alpha$, Sci. Rep., 2020, 10, 11790.

56 F. Bondarian, A. Ebrahimi, F. Mahjoubi, E. Hervan and R. Gonbad, Evaluation of phytochemical content of white tea clone 100 and changes the expression of tumor suppressor genes on colorectal cancer cell line HCT116, Pharmacogn. Res., 2019, 11, 224.

57 L. Liu, B. Liu, J. Li, S. Zhen, Z. Ye, M. Cheng and W. Liu, Responses of Different Cancer Cells to White Tea Aqueous Extract: Response to white tea aqueous extract..., J. Food Sci., 2018, 83, 2593-2601.

58 C. Musial, A. Kuban-Jankowska and M. GorskaPonikowska, Beneficial Properties of Green Tea Catechins, Int. J. Mol. Sci., 2020, 21, 1744.

59 S. M. Henning, P. Wang, R.-P. Lee, A. Trang, G. Husari, J. Yang, E. M. Grojean, A. Ly, M. Hsu, D. Heber, T. Grogan, Z. Li and W. J. Aronson, Prospective randomized trial evaluating blood and prostate tissue concentrations of green tea polyphenols and quercetin in men with prostate cancer, Food Funct., 2020, 11, 4114-4122. 
60 V. S. Rogovskii, S. V. Popov, N. V. Sturov and N. L. Shimanovskii, The Possibility of Preventive and Therapeutic Use of Green Tea Catechins in Prostate Cancer, Anticancer Agents Med. Chem., 2019, 19, 12231231.

61 Y. Miyata, Y. Shida, T. Hakariya and H. Sakai, Anti-Cancer Effects of Green Tea Polyphenols Against Prostate Cancer, Molecules, 2019, 24, 193.

62 S. Yu, L. Zhu, K. Wang, Y. Yan, J. He and Y. Ren, Green tea consumption and risk of breast cancer: A systematic review and updated meta-analysis of case-control studies, Medicine, 2019, 98, e16147.

63 Y. Wang, Y. Zhao, F. Chong, M. Song, Q. Sun, T. Li, L. Xu and C. Song, A dose-response meta-analysis of green tea consumption and breast cancer risk, Int. J. Food Sci. Nutr., 2020, 71, 656-667.

64 Y. Shirakami and M. Shimizu, Possible Mechanisms of Green Tea and Its Constituents against Cancer, Molecules, 2018, 23, 2284.

65 V. Gianfredi, D. Nucci, A. Abalsamo, M. Acito, M. Villarini, M. Moretti and S. Realdon, Green Tea Consumption and Risk of Breast Cancer and Recurrence-A Systematic Review and Meta-Analysis of Observational Studies, Nutrients, 2018, 10, 1886.

66 T. Filippini, M. Malavolti, F. Borrelli, A. A. Izzo, S. J. Fairweather-Tait, M. Horneber and M. Vinceti, Green tea (Camellia sinensis) for the prevention of cancer, Cochrane Database Syst. Rev., 2020, 3.

67 E. Tomaszewska, S. Muszyński, P. Dobrowolski, A. Winiarska-Mieczan, M. Kwiecień, A. Tomczyk-Warunek, M. Ejtel, I. Świetlicka and B. Gładyszewska, White Tea is More Effective in Preservation of Bone Loss in Adult Rats Co-Exposed to Lead and Cadmium Compared to Black, Red or Green Tea, Ann. Anim. Sci., 2018, 18, 937953.

68 M. D. McAlpine, W. Gittings, A. J. MacNeil and W. E. Ward, Black and Green Tea as Well as Specialty Teas Increase Osteoblast Mineralization with Varying Effectiveness, J. Med. Food, 2020, DOI: 10.1089/ jmf.2020.0139.

69 S.-Y. Lin, J. Y. Kan, C.-C. Lu, H. H. Huang, T.-L. Cheng, H.-T. Huang, C.-J. Ho, T.-C. Lee, S.-C. Chuang, Y.-S. Lin, L. Kang and C.-H. Chen, Green Tea Catechin (-)-Epigallocatechin-3-Gallate (EGCG) Facilitates Fracture Healing, Biomolecules, 2020, 10, 620.

70 R. Kiyama, Estrogenic biological activity and underlying molecular mechanisms of green tea constituents, Trends Food Sci. Technol., 2020, 95, 247-260.

71 W. C. Reygaert, Green Tea Catechins: Their Use in Treating and Preventing Infectious Diseases, BioMed Res. Int., 2018, 2018, 1-9.

72 R. Ghosh, A. Chakraborty, A. Biswas and S. Chowdhuri, Evaluation of green tea polyphenols as novel corona virus (SARS CoV-2) main protease (Mpro) inhibitors - an in silico docking and molecular dynamics simulation study, J. Biomol. Struct. Dyn., 2020, 1-13.
73 K. Kaihatsu, M. Yamabe and Y. Ebara, Antiviral Mechanism of Action of Epigallocatechin-3-O-gallate and Its Fatty Acid Esters, Molecules, 2018, 23(10), 2475.

74 N. Miyoshi, H. Tanabe, T. Suzuki, K. Saeki and Y. Hara, Applications of a Standardized Green Tea Catechin Preparation for Viral Warts and Human Papilloma VirusRelated and Unrelated Cancers, Molecules, 2020, 25, 2588.

75 S. Onishi, T. Mori, H. Kanbara, T. Habe, N. Ota, Y. Kurebayashi and T. Suzuki, Green tea catechins adsorbed on the murine pharyngeal mucosa reduce influenza A virus infection, J. Funct. Foods, 2020, 68, 103894.

76 P. Mahajan, S. Tomar, A. Kumar, N. Yadav, A. Arya and V. D. Dwivedi, A multi-target approach for discovery of antiviral compounds against dengue virus from green tea, Netw. Model. Anal. Health Inform. Bioinf., 2020, 9, 20.

77 S. Liao, Y. Tang, C. Chu, W. Lu, B. Baligen, Y. Man and Y. Qu, Application of green tea extracts epigallocatechin-3gallate in dental materials: Recent progress and perspectives, J Biomed Mater Res, Part A, 2020, 108, 2395-2408.

78 F. Kalalinia, N. Amiri, N. Mehrvarzian, B. S. Fazly Bazzaz, M. Iranshahi, A. Shahroodi, S. Arabzadeh, M. Abbaspour, S. Badiee Aaval and J. Movaffagh, Topical green tea formulation with anti-hemorrhagic and antibacterial effects, Iran. J. Basic Med. Sci., 2020, 23(8), 1085.

79 S. Ghorbanoghli, S. A. Hashemi, S. Amirkhanloo, A. Rezaei, A. H. Shahmirzadi, N. Nazemi, S. Bybordi, A. Piranviseh, H. Akbari and S. Nazemi, Clinical Properties of Green Tea: Focus on Blood Lipid Profiles, Analgesia, Periodontal Status, J. Res. Med. Dent. Sci., 2019, 7, 32-43.

80 G. Radafshar, M. Ghotbizadeh, F. Saadat and N. Mirfarhadi, Effects of green tea (Camellia sinensis) mouthwash containing $1 \%$ tannin on dental plaque and chronic gingivitis: a double-blinded, randomized, controlled trial, J. Investig. Clin. Dent., 2017, 8, e12184.

81 A. Kusumawardani, S. Sukmasari, N. Akmal Abdul Mutalib, S. Fatihah Abdul Rahman and S. Jauhari Arief Ichwan, Comparative study of antimicrobial potential of White tea and Black tea leaf extracts from East JavaIndonesia on two species of oral streptococci, Mater. Today Proc., 2019, 16, 2226-2230.

82 H. Nanri, Y. Yamada, A. Itoi, E. Yamagata, Y. Watanabe, T. Yoshida, M. Miyake, H. Date, K. Ishikawa-Takata, M. Yoshida, T. Kikutani and M. Kimura, Consumption of green tea but not coffee is associated with the oral healthrelated quality of life among an older Japanese population: Kyoto-Kameoka cross-sectional study, Eur. J. Clin. Nutr., 2019, 73, 577-584.

83 M. M. Vilela, S. L. Salvador, I. G. L. Teixeira, M. C. G. Del Arco and A. De Rossi, Efficacy of green tea and its extract, epigallocatechin-3-gallate, in the reduction of cariogenic microbiota in children: a randomized clinical trial, Arch. Oral Biol., 2020, 114, 104727.

84 S. Kim, T. H. Park, W. I. Kim, S. Park, J. H. Kim and M. K. Cho, The effects of green tea on acne vulgaris: A sys- 
tematic review and meta-analysis of randomized clinical trials, Phytother. Res., 2021, 35(1), 374-383.

85 L. Xing, H. Zhang, R. Qi, R. Tsao and Y. Mine, Recent Advances in the Understanding of the Health Benefits and Molecular Mechanisms Associated with Green Tea Polyphenols, J. Agric. Food Chem., 2019, 67, 1029-1043.

86 F. M. Shams Olmolouk Jalalmanesh, The Effect of Green Tea On Mental Health of Nurses Working in Selected Hospitals of Hamadan University of Medical Sciences, Indo Am. J. Pharm. Sci., 2017, 04(09), 2881-2886.

87 Y. Shirai, K. Kuriki, R. Otsuka, Y. Kato, Y. Nishita, C. Tange, M. Tomida, T. Imai, F. Ando and H. Shimokata, Green tea and coffee intake and risk of cognitive decline in older adults: The National Institute for Longevity Sciences, Longitudinal Study of Aging, Public Health Nutr., 2020, 23, 1049-1057.

88 J. L. Williams, J. M. Everett, N. M. D’Cunha, D. Sergi, E. N. Georgousopoulou, R. J. Keegan, A. J. McKune, D. D. Mellor, N. Anstice and N. Naumovski, The Effects of Green Tea Amino Acid L-Theanine Consumption on the Ability to Manage Stress and Anxiety Levels: A Systematic Review, Plant Foods Hum. Nutr., 2020, 75, 12-23.

89 K. Unno, D. Furushima, Y. Nomura, H. Yamada, K. Iguchi, K. Taguchi, T. Suzuki, M. Ozeki and Y. Nakamura, Antidepressant Effect of Shaded White Leaf Tea Containing High Levels of Caffeine and Amino Acids, Molecules, 2020, 25, 3550.

90 A. R. Khalatbary and E. Khademi, The green tea polyphenolic catechin epigallocatechin gallate and neuroprotection, Nutr. Neurosci., 2020, 23, 281-294.

91 Y. Yoneda, N. Kuramoto and K. Kawada, The role of glutamine in neurogenesis promoted by the green tea amino acid theanine in neural progenitor cells for brain health, Neurochem. Int., 2019, 129, 104505.

92 S. Kakutani, H. Watanabe and N. Murayama, Green tea intake and risks for dementia, Alzheimer's disease, mild cognitive impairment, and cognitive impairment: A systematic review, Nutrients, 2019, 11, 1165.

93 E. J. Okello and J. Mather, Comparative Kinetics of Acetyland Butyryl-Cholinesterase Inhibition by Green Tea Catechins|Relevance to the Symptomatic Treatment of Alzheimer's Disease, Nutrients, 2020, 12, 1090.

94 S.-B. Lee, E.-H. Choi, K.-H. Jeong, K.-S. Kim, S.-M. Shim and G.-H. Kim, Effect of catechins and high-temperatureprocessed green tea extract on scavenging reactive oxygen species and preventing A $\beta 1-42$ fibrils' formation in brain microvascular endothelium, Nutr. Neurosci., 2020, 23, 363-373.

95 X. Li, S. D. Smid, J. Lin, Z. Gong, S. Chen, F. You, Y. Zhang, Z. Hao, H. Lin, X. Yu and X. Jin, Neuroprotective and Anti-Amyloid $\beta$ Effect and Main Chemical Profiles of White Tea: Comparison Against Green, Oolong and Black Tea, Molecules, 2019, 24, 1926.

96 S. A. Almatroodi, A. Almatroudi, M. A. Alsahli, M. A. Aljasir, M. A. Syed and A. H. Rahmani, Epigallocatechin-3-Gallate (EGCG), an Active Compound of Green Tea Attenuates Acute Lung Injury Regulating Macrophage Polarization and Krüpple-Like-Factor 4 (KLF4) Expression, Molecules, 2020, 25, 2853.

97 S. Rahman, Y. Huang, L. Zhu, S. Feng, I. Khan, J. Wu, Y. Li and X. Wang, Therapeutic Role of Green Tea Polyphenols in Improving Fertility: A Review, Nutrients, 2018, 10, 834.

98 L. Sun, H. Xu, J. Ye and N. W. Gaikwad, Comparative effect of black, green, oolong, and white tea intake on weight gain and bile acid metabolism, Nutrition, 2019, 65, 208-215.

99 W. Y. Khoo, B. J. Chrisfield, S. Sae-tan and J. D. Lambert, Mitigation of nonalcoholic fatty liver disease in high-fatfed mice by the combination of decaffeinated green tea extract and voluntary exercise, J. Nutr. Biochem., 2020, 76, 108262.

100 M. Mahmoodi, R. Hosseini, A. Kazemi, R. Ofori-Asenso, M. Mazidi and S. M. Mazloomi, Effects of green tea or green tea catechin on liver enzymes in healthy individuals and people with nonalcoholic fatty liver disease: A systematic review and meta-analysis of randomized clinical trials, Phytother. Res., 2020, 34, 1587-1598.

101 R. Wang, Z. Yang, J. Zhang, J. Mu, X. Zhou and X. Zhao, Liver Injury Induced by Carbon Tetrachloride in Mice Is Prevented by the Antioxidant Capacity of Anji White Tea Polyphenols, Antioxidants, 2019, 8, 64.

102 W. Dekant, K. Fujii, E. Shibata, O. Morita and A. Shimotoyodome, Safety assessment of green tea based beverages and dried green tea extracts as nutritional supplements, Toxicol. Lett., 2017, 277, 104-108.

103 Z. Bedrood, M. Rameshrad and H. Hosseinzadeh, Toxicological effects of Camellia sinensis (green tea): A review, Phytother. Res., 2018, 32, 1163-1180.

104 J. Hu, D. Webster, J. Cao and A. Shao, The safety of green tea and green tea extract consumption in adults - Results of a systematic review, Regul. Toxicol. Pharmacol., 2018, 95, 412-433.

105 EFSA Panel on Food Additives and Nutrient Sources added to Food (ANS), M. Younes, P. Aggett, F. Aguilar, R. Crebelli, B. Dusemund, M. Filipič, M. J. Frutos, P. Galtier, D. Gott, U. Gundert-Remy, C. Lambré, J. Leblanc, I. T. Lillegaard, P. Moldeus, A. Mortensen, A. Oskarsson, I. Stankovic, I. Waalkens-Berendsen, R. A. Woutersen, R. J. Andrade, C. Fortes, P. Mosesso, P. Restani, D. Arcella, F. Pizzo, C. Smeraldi and M. Wright, Scientific opinion on the safety of green tea catechins, EFSA J., 2018, 16(4), e05239.

106 T. Kiss, Z. Timár, A. Szabó, A. Lukács, V. Velky, G. Oszlánczi, E. Horváth, I. Takács, I. Zupkó and D. Csupor, Effect of green tea on the gastrointestinal absorption of amoxicillin in rats, BMC Pharmacol. Toxicol., 2019, 20, 54.

107 T. Shah, J. Warsi and Z. Laghari, Tea drinking and its cooccurrence with anemia in pregnant females -, Rawal Med. J., 2020, 45, 163-167.

108 S. N. Kumar, S. Raisuddin, Kh. J. Singh, B. Bastia, D. Borgohain, L. Teron, S. K. Sharma and A. K. Jain, 
Association of maternal determinants with low birth weight babies in tea garden workers of Assam, J. Obstet. Gynaecol. Res., 2020, 46, 715-726.

109 M. Hahn, M. Baierle, M. F. Charão, G. B. Bubols, F. S. Gravina, P. Zielinsky, M. D. Arbo and S. Cristina Garcia, Polyphenol-rich food general and on pregnancy effects: a review, Drug Chem. Toxicol., 2017, 40, 368-374.

110 J.-H. Lu, J.-R. He, S.-Y. Shen, X.-L. Wei, N.-N. Chen, M.-Y. Yuan, L. Qiu, W.-D. Li, Q.-Z. Chen, C.-Y. Hu, H.-M. Xia, S. Bartington, K. K. Cheng, K. B. H. Lam, $\mathrm{X}$. Qiu and the Born in Guangzhou Cohort Study Group, Does tea consumption during early pregnancy have an adverse effect on birth outcomes?, Birth, 2017, 44, 281289.

111 S. R. F. Pedra, P. Zielinsky, C. N. Binotto, C. N. Martins, E. da Fonseca and I. C. B. Guimarães, Diretriz Brasileira de Cardiologia Fetal-2019, Arq. Bras. Cardiol., 2019, 112, 600-648.

112 R. Wierzejska, M. Jarosz and B. Wojda, Caffeine Intake During Pregnancy and Neonatal Anthropometric Parameters, Nutrients, 2019, 11, 806.

113 M. A. Farag, A. Abdelwareth, I. E. Sallam, M. el Shorbagi, N. Jehmlich, K. Fritz-Wallace, S. Serena Schäpe, U. RolleKampczyk, A. Ehrlich, L. A. Wessjohann and M. von Bergen, Metabolomics reveals impact of seven functional foods on metabolic pathways in a gut microbiota model, J. Adv. Res., 2020, 23, 47-59.

114 Y. T. Loo, K. Howell, M. Chan, P. Zhang and K. Ng, Modulation of the human gut microbiota by phenolics and phenolic fiber-rich foods, Compr. Rev. Food Sci. Food Saf., 2020, 19, 1268-1298.

115 Y.-C. Liu, X.-Y. Li and L. Shen, Modulation effect of tea consumption on gut microbiota, Appl. Microbiol. Biotechnol., 2020, 104, 981-987.

116 G. Ma and Y. Chen, Polyphenol supplementation benefits human health via gut microbiota: A systematic review via meta-analysis, J. Funct. Foods, 2020, 66, 103829.

117 G. Annunziata, M. Maisto, C. Schisano, R. Ciampaglia, P. Daliu, V. Narciso, G. Tenore and E. Novellino, Colon Bioaccessibility and Antioxidant Activity of White, Green and Black Tea Polyphenols Extract after In Vitro Simulated Gastrointestinal Digestion, Nutrients, 2018, 10, 1711.

118 E. Valero-Cases, D. Cerdá-Bernad, J.-J. Pastor and M.-J. Frutos, Non-Dairy Fermented Beverages as Potential
Carriers to Ensure Probiotics, Prebiotics, and Bioactive Compounds Arrival to the Gut and Their Health Benefits, Nutrients, 2020, 12, 1666.

119 J. Zhu, R. Cai, Y. Tan, X. Wu, Q. Wen, Z. Liu, S.-H. Ouyang, Z. Yin and H. Yang, Preventive consumption of green tea modifies the gut microbiota and provides persistent protection from high-fat diet-induced obesity, J. Funct. Foods, 2020, 64, 103621.

120 M. L. Y. Wan, V. A. Co and H. El-Nezami, Dietary polyphenol impact on gut health and microbiota, Crit. Rev. Food Sci. Nutr., 2020, 1-22.

121 Y. Li, S. U. Rahman, Y. Huang, Y. Zhang, P. Ming, L. Zhu, X. Chu, J. Li, S. Feng, X. Wang and J. Wu, Green tea polyphenols decrease weight gain, ameliorate alteration of gut microbiota, and mitigate intestinal inflammation in canines with high-fat-diet-induced obesity, J. Nutr. Biochem., 2020, 78, 108324.

122 R. Yan, C. Ho and X. Zhang, Interaction between Tea Polyphenols and Intestinal Microbiota in Host Metabolic Diseases from the Perspective of the Gut-Brain Axis, Mol. Nutr. Food Res., 2020, 64, 2000187.

123 L. Zhang, R. Yan and Z. Wu, Metagenomics analysis of intestinal flora modulatory effect of green tea polyphenols by a circadian rhythm dysfunction mouse model, J. Food Biochem., 2020, 44(10), e13430.

124 S. Pérez-Burillo, D. Hinojosa-Nogueira, S. Pastoriza and J. A. Rufián-Henares, Plant extracts as natural modulators of gut microbiota community structure and functionality, Heliyon, 2020, 6, e05474.

125 L. Godočiková, The impact of addition of different tea powders on the biological value of white chocolates, J. Microbiol., Biotechnol. Food Sci., 2019, 9, 396-399.

126 J. M. Lorenzo and P. E. S. Munekata, Phenolic compounds of green tea: Health benefits and technological application in food, Asian Pac. J. Trop. Biomed., 2016, 6, 709719.

127 L. Purnamayanti, J. Jamhari, C. Hanim and A. Irawan, Physicochemical Properties, Oxidative Stability, and Sensory Quality of Lamb Sausage Added with Green Tea Leaves (Camelia sinensis) Powder, Trop. J. Anim. Sci., 2020, 43, 57-63.

128 J. Wang, R. Jia, P. Celi, X. Ding, S. Bai, Q. Zeng, X. Mao, $\mathrm{S}$. Xu and K. Zhang, Green tea polyphenol epigallocatechin-3-gallate improves the antioxidant capacity of eggs, Food Funct., 2020, 11, 534-543. 